\title{
Upper ocean climate of the Eastern Mediterranean Sea during the Holocene Insolation Maximum - a model study
}

\author{
F. Adloff ${ }^{1,2}$, U. Mikolajewicz ${ }^{1}$, M. Kučera ${ }^{3}$, R. Grimm ${ }^{1,2}$, E. Maier-Reimer ${ }^{1}$, G. SchmiedI ${ }^{4}$, and K.-C. Emeis ${ }^{5}$ \\ ${ }^{1}$ Max Planck Institute for Meteorology, Hamburg, Germany \\ ${ }^{2}$ International Max Planck Research School on Earth System Modelling, Hamburg, Germany \\ ${ }^{3}$ University of Tübingen, Department of Geosciences, Tübingen, Germany \\ ${ }^{4}$ University of Hamburg, Department of Geosciences, Hamburg, Germany \\ ${ }^{5}$ University of Hamburg, Institute for Biogeochemistry and Marine Chemistry, Hamburg, Germany
}

Received: 25 March 2011 - Published in Clim. Past Discuss.: 5 May 2011

Revised: 22 September 2011 - Accepted: 26 September 2011 - Published: 21 October 2011

\begin{abstract}
Nine thousand years ago (9 ka BP), the Northern Hemisphere experienced enhanced seasonality caused by an orbital configuration close to the minimum of the precession index. To assess the impact of this "Holocene Insolation Maximum" (HIM) on the Mediterranean Sea, we use a regional ocean general circulation model forced by atmospheric input derived from global simulations. A stronger seasonal cycle is simulated by the model, which shows a relatively homogeneous winter cooling and a summer warming with well-defined spatial patterns, in particular, a subsurface warming in the Cretan and western Levantine areas.

The comparison between the SST simulated for the HIM and a reconstruction from planktonic foraminifera transfer functions shows a poor agreement, especially for summer, when the vertical temperature gradient is strong. As a novel approach, we propose a reinterpretation of the reconstruction, to consider the conditions throughout the upper water column rather than at a single depth. We claim that such a depth-integrated approach is more adequate for surface temperature comparison purposes in a situation where the upper ocean structure in the past was different from the present-day. In this case, the depth-integrated interpretation of the proxy data strongly improves the agreement between modelled and reconstructed temperature signal with the subsurface summer warming being recorded by both model and proxies, with a small shift to the south in the model results.
\end{abstract}

Correspondence to: F. Adloff (fanny.adloff@zmaw.de)
The mechanisms responsible for the peculiar subsurface pattern are found to be a combination of enhanced downwelling and wind mixing due to strengthened Etesian winds, and enhanced thermal forcing due to the stronger summer insolation in the Northern Hemisphere. Together, these processes induce a stronger heat transfer from the surface to the subsurface during late summer in the western Levantine; this leads to an enhanced heat piracy in this region, a process never identified before, but potentially characteristic of time slices with enhanced insolation.

\section{Introduction}

During the early Holocene, the Northern Hemisphere climate experienced an enhanced seasonality of insolation. This period here is referred to as the Holocene Insolation Maximum (HIM) because of the high insolation rate occurring in northern hemisphere summer. The stronger seasonality of the insolation was associated with a strengthening of the North African monsoon (e.g. Rossignol-Strick, 1983).

Coincidental with the strengthened orbital forcing, sediment cores from the Eastern Mediterranean Sea display a dark sediment layer, rich in organic carbon, called sapropel S1, deposited between approximately 9 and $6 \mathrm{kaBP}$ (e.g. Mercone et al., 2000). The sapropel S1 and earlier equivalents reflect low oxygen availability in the deep Eastern Mediterranean basin. One of the hypothesis for the sapropel formation is that a freshening of the Mediterranean surface water induced a decrease in surface density and, thus, prevented the ventilation of deeper layers through the

Published by Copernicus Publications on behalf of the European Geosciences Union. 
reduced/absent formation of dense deep water, promoting the preservation of organic matter in the sediment (e.g. Rohling and Hilgen, 1991; Rohling, 1994; Cramp and O'Sullivan, 1999).

Because of its isolated configuration, the Mediterranean Sea, as a "mini-ocean", is thought to show a rapid and amplified response to past or future climate changes and can be used as a "laboratory" for modelling climate changes. However, only few paleo-modelling studies have investigated the effect of changes in atmospheric forcing on the Mediterranean. Both Bigg (1994) and Mikolajewicz (2011) used a regional ocean general circulation model (OGCM) forced by fluxes interactively calculated from bulk formulas with atmospheric input data from a coarse resolution atmospheric model to simulate the ocean climate of the Last Glacial Maximum (LGM) for the Mediterranean. Meijer and Tuenter (2007) forced their OGCM with present-day realistic climate and adjusted the runoff and precipitation minus evaporation $(P-E)$ values to precession minimum conditions; those adjustments were based on experiments performed with an earth system model of intermediate complexity. Myers et al. (1998) and Myers and Rohling (2002) forced a regional OGCM with both modified sea surface temperature (SST) and salinity (SSS) according to reconstructions. Their studies focused on the LGM and the early Holocene. Meijer and Dijkstra (2009) forced their regional OGCM with strongly idealized atmospheric forcing to mimic the effect of a past climate change. Finally, Myers (2002) forced its Mediterranean OGCM with artificial surface fluxes of heat and freshwater to investigate changes in excess evaporation.

Our modelling strategy aims at simulating the Mediterranean ocean climate of the HIM ( $9 \mathrm{ka} \mathrm{BP})$. This time slice has been chosen for several reasons. First, the HIM represents a typical past climate with enhanced seasonality and particularly warmer summers, whose influence on the Mediterranean ocean climate needs to be assessed, in today's context of global warming. Second, a newly compiled dataset of upper-ocean temperature reconstructed from foraminifera has identified a pronounced warm anomaly pattern in summer SST around Crete for the time slice 8.5$9.5 \mathrm{ka}$ BP (see Kucera et al., 2011). Here, we would like to investigate the mechanisms driving this pattern through modelling. Third, we already have global simulations which represent a reasonable early Holocene climate, so we can use them to force our Mediterranean ocean model. This exercise tests the adequacy of simulating a regional past climate state by using an atmospheric forcing extracted from global model simulations, whose resolution is more than one order of magnitude lower than the one of the regional ocean model. Finally, the HIM Mediterranean simulation can be used at a future stage as a baseline to test the hypotheses for sapropel formation, through freshwater perturbation experiments.

For the above-detailed reasons, we carry out and validate simulations for the HIM climate. To assess the performance of the Mediterranean ocean model when it is forced by atmospheric input from coarse resolution global simulations, we perform a comparison with the dataset of reconstructed upper-ocean temperature from Kucera et al. (2011). We investigate the changes in ocean climate that are simulated in response to an atmospheric forcing representing the HIM.The focus lies on the upper ocean of the Eastern Mediterranean.

To achieve a proper comparison of model output with reconstructed quantities, the model has to be free from any information from paleo-reconstructions. We, therefore, follow a similar approach as Bigg (1994) and Mikolajewicz (2011). We use a regional OGCM which is forced by fluxes calculated with bulk formulas, using atmospheric input data derived from long-term simulations with a coupled global atmosphere-ocean-vegetation model. Not presented here, a future study will test the hypotheses for sapropel S1 formation by performing freshwater perturbation experiments against the validated baseline to assess the plausible physical mechanisms leading to a weakening/shutdown of the deep ventilation.

The goals of the present study are the following: (i) to analyse the modelled changes in the upper-ocean state during the "Holocene Insolation Maximum", (ii) to investigate the physical mechanisms responsible for strong regional contrasts of the modelled temperature signal, (iii) to validate the modelling results with sea-surface temperature reconstructions.

The paper is organized as follows: in Sect. 2 model, forcing and experiments are described. Key quantities of the obtained model control climate are compared to observations in Sect. 3. The results for the HIM are described, analysed and compared to reconstructions in Sect. 4.

\section{Model, forcing and experiments}

\subsection{The regional OGCM}

For this study, we use the Mediterranean configuration of the ocean general circulation model MPIOM (Max-PlanckInstitute Ocean Model) which has been used by Mikolajewicz (2011). The three-dimensional primitive equation hydrostatic ocean model MPIOM is described in detail in Marsland et al. (2003). For the horizontal discretization, an orthogonal curvilinear Arakawa C-grid is used (Arakawa and Lamb, 1977). The treatment of subgridscale mixing is done with an isopycnal diffusion scheme; at the surface, a simple mixed layer scheme is included to account for the effect of the wind mixing; in the interior, the Richardson number dependant mixing term follows the PP scheme (Pacanowski and Philander, 1981). Convective adjustment is treated by an enhanced vertical diffusion coefficient for tracers $\left(0.5 \mathrm{~m}^{2} \mathrm{~s}^{-1}\right)$. The model grid covers the entire Mediterranean Sea including the Black Sea and a small area of the Atlantic, west of Gibraltar (Fig. 1). The grid is curvilinear with a horizontal 


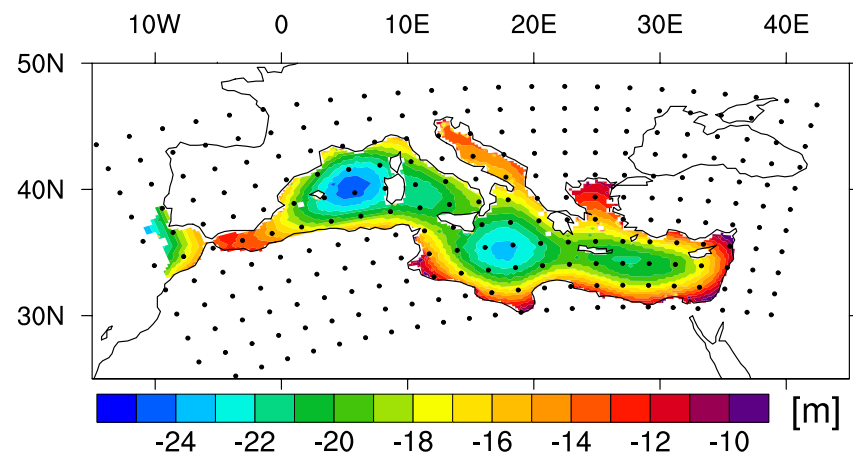

Fig. 1. Topography changes between $9 \mathrm{~K}$ and CTRL. The superimposed dots represent 1 of each 10 grid box centre of the model in each direction.

resolution of roughly $20 \mathrm{~km}$. We use a 29 -level z-coordinates system, with 5 levels within the upper $54 \mathrm{~m}$. The thickness of the first ocean layer is $12 \mathrm{~m}$ plus sea level. The model SST is centred at $6 \mathrm{~m}$ depth. The time step is $36 \mathrm{~min}$.

The topography is realistic, the Strait of Gibraltar and the Bosphorus are both represented by one grid point and their sills have depths of 256 and $21 \mathrm{~m}$, respectively, in the topography used for the pre-industrial climate simulation. During the early Holocene, the sea level was approximatively $20 \mathrm{~m}$ lower than today. To account for this in the paleosimulations, we reduced the depth by modifying the Mediterranean Sea topography according to the ICE-5G reconstruction from Peltier (2004) (Fig. 1). Moreover, we assume the Bosphorus to be closed at this time, so that there is no outflow of fresher water from the Black Sea into the Marmara Sea. We base this assumption on the study from Ryan et al. (1997) who consider a catastrophic inflow of water from Mediterranean into Black Sea happening around $8.4 \mathrm{kaBP}$, and the study from Sperling et al. (2003) who reconstructed high salinities in the Marmara Sea for S1 sapropel time. However, other studies contradict this statement; Aksu et al. (2002), for instance, suggest an overflow from the Black Sea into the Marmara Sea from $10.5 \mathrm{ka}$ BP onwards with low salinities found in the Marmara Sea. A recent study by Soulet et al. (2011) suggests a reconnection at around $9 \mathrm{ka} \mathrm{BP}$.

\subsection{Atmospheric forcing and boundary conditions}

At the surface, the Mediterranean regional OGCM is forced by air-sea fluxes of heat, momentum and water. The heat fluxes are calculated from daily atmospheric data with bulk formulas according to da Silva et al. (1994).

The atmospheric forcing is derived from long-term simulations performed with the coupled global circulation model ECHAM5/MPIOM/LPJ in a global setup (Mikolajewicz et al., 2007). The atmosphere component ECHAM5 (Roeckner et al., 2003) has a T31 horizontal resolution and 19 vertical levels; the ocean component MPIOM has a curvilinear grid with poles over Greenland and Antarctica. The horizontal resolution of MPIOM is roughly $3^{\circ}$, and there are 40 vertical levels. The dynamical vegetation component LPJ has the same horizontal resolution as the atmosphere component.

\subsubsection{Global model setup}

The simulations with the global model are carried out until equilibrium for the pre-industrial climate and for two different simulations of the HIM. The reference simulation refers to a pre-industrial type climate. Following the PMIP2 protocol (Braconnot et al., 2007), the atmospheric partial pressure of $\mathrm{CO}_{2}\left(p \mathrm{CO}_{2}\right)$ is set to $280 \mathrm{ppm}$ and the insolation corresponds to 1950 (changes in the orbital parameters lead to negligible insolation differences between 1750 and 1950). For the HIM (9 ka BP), the global simulation used to force the "9K1" regional simulation only considers changes in insolation. In the HIM global simulation used to force the "9K2" regional simulation, besides the changes in earth orbital parameters, the atmospheric $p \mathrm{CO}_{2}$ is set to $260 \mathrm{ppm}$ instead of $280 \mathrm{ppm}$ and the topography is modified using ice sheet distributions and topography changes according to the ICE-5G reconstruction (Peltier, 2004).

From these global simulations, we derive three different sets of atmospheric forcing input: one for the pre-industrial climate used as control climate (CTRL) and two for the HIM climate (9K1 and 9K2).

We extract a 100-yr daily atmospheric forcing dataset with the following variables: precipitation, incoming short wave radiation, cloud cover, near-surface air temperature, dew point temperature, $10-\mathrm{m}$ wind speed and sea level pressure. Due to the coarse resolution of the global coupled model, simulated wind stress patterns are too smooth over the Mediterranean Sea. Therefore, we apply a statistical downscaling to calculate the wind stress from the sea level pressure (SLP) of the global model. For the statistical downscaling, we use the SLP and wind stress from NCEP reanalysis data for the period 1978-2002 (Kalnay et al., 1996). We consider daily data of SLP of the Mediterranean and adjacent regions (truncated on the T31-grid of the global model), and wind stress interpolated onto the ocean model grid. First, we subtract the long-term mean from the data to obtain anomalies of the NCEP data. Then we calculate a linear regression between principal component time series of empirical orthogonal functions (EOFs, von Storch and Zwiers, 1999) of (i) the anomalies of SLP data from NCEP and (ii) the anomalies of wind stress data from NCEP. Afterward, SLP anomalies from the coarse resolution global model are projected onto the EOFs. Wind stress anomalies are estimated from the obtained loadings using the regression matrix obtained from the NCEP reanalysis. Finally, the wind stress anomalies are added to the long-term mean of NCEP reanalysis data.

As the global model has a cold bias over the Mediterranean, the systematic bias between the model and the NCEP 


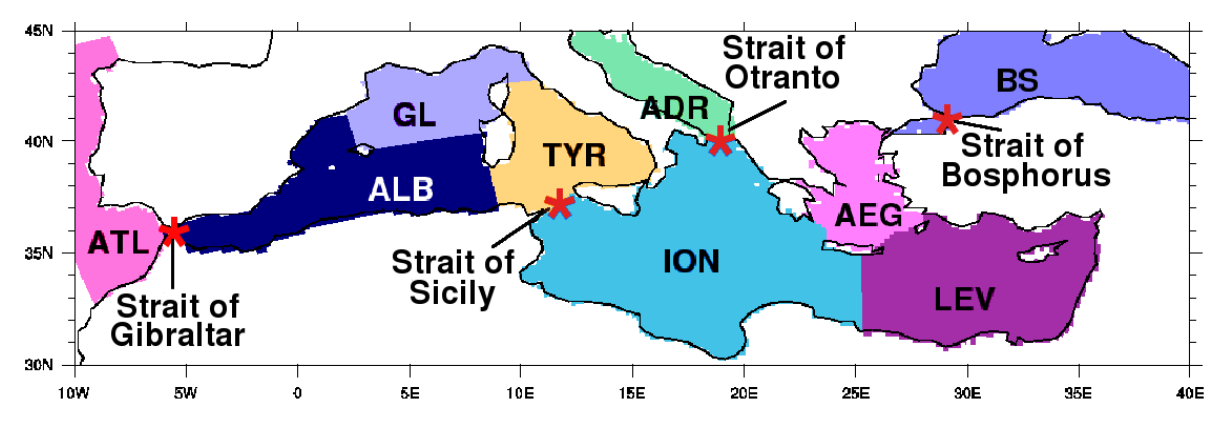

Fig. 2. Sub-basins of the Mediterranean: Gulf of Lion (GL), Alboran Sea (ALB), Tyrrhenian Sea (TYR), Adriatic Sea (ADR), Ionian Sea (ION), Aegean Sea (AEG), Levantine Sea (LEV). The Atlantic box (ATL) and the Black Sea (BS) are shown as well. The main straits are marked with a red star.

climatology is added to the actual model values for nearsurface air temperature and dew point temperature.

\subsubsection{Freshwater fluxes and restoring}

The components of the water fluxes are the monthly prescribed river runoff $(R)$, the precipitation $(P)$ from the atmospheric data derived from the global model, and the evaporation $(E)$ calculated from the latent heat flux using model SST. For the river discharge, we use a 1-yr monthly climatology from the UNESCO RivDis database (Vörösmarty et al., 1998). The seasonal cycle is taken into account only for the major rivers (Danube, Nile, Dniepr, Rhone, Po and Ebro). For the Nile and the Ebro rivers, we consider discharge rates prior to the damming, with a yearly averaged runoff of $2930 \mathrm{~m}^{3} \mathrm{~s}^{-1}$ for the Nile and $410 \mathrm{~m}^{3} \mathrm{~s}^{-1}$ for the Ebro. For the HIM simulations, the anomalies (9 K vs. CTRL) of the river discharge simulated by the coupled model are superimposed on the monthly climatology of river runoff used for the CTRL experiment.

At the surface, there is no restoring to SST and SSS. At the western margin of the Atlantic box, a restoring to climatological monthly temperature and salinity from World Ocean Atlas (WOA, Levitus et al., 1998) is applied over 5 grid cells. For the paleo-simulations, the same procedure is applied as for the runoff: the anomalies ( $9 \mathrm{~K}$ vs. CTRL) of the Atlantic hydrography from the global model experiments are superimposed to the values used in CTRL.

The evaporation is varying, depending on the latent heat flux, which is a function of the SST. As the freshwater fluxes also affect sea level due to the mass flux boundary condition, the net evaporation of the Mediterranean would lead to a continuously decreasing sea level. To account for this, we perform a sea level restoring in the 5 most western grid cells of the Atlantic buffer zone, thus, ensuring that the net water transport through the Strait of Gibraltar corresponds to the net water loss in the Mediterranean and the Black Sea.

\subsection{Spin-up and initial conditions}

The integration time strongly differs between the already existing studies: $25 \mathrm{yr}$ for Bigg (1994), $20 \mathrm{yr}$ for Meijer and Tuenter (2007), $100 \mathrm{yr}$ for Myers et al. (1998) and Myers and Rohling (2002), $1000 \mathrm{yr}$ for Meijer and Dijkstra (2009) and $1999 \mathrm{yr}$ for Mikolajewicz (2011). A long spinup is essential to reach an ocean state which is no longer drifting from the surface to intermediate depths. We, therefore, perform $700 \mathrm{yr}$ simulations with the Mediterranean OGCM.

We start the three simulations from an initial state with homogeneous low density water $\left(20^{\circ} \mathrm{C}\right.$ and $38 \mathrm{~g} \mathrm{~kg}^{-1}$ for the Mediterranean and the Atlantic box; $20^{\circ} \mathrm{C}$ and $20 \mathrm{~g} \mathrm{~kg}^{-1}$ for the Black Sea) and let the model run in a free mode for $700 \mathrm{yr}$, forced by the 100-yr daily atmospheric dataset repeated in a loop. Such initial conditions allow the model to form its own water masses without being under the influence of starting hydrographic conditions derived from a climatology. Because these experiments were started from homogeneous light water and the forcing is not transient, our simulations can only lead to an ocean state with an active deep circulation as stationary solution, because cross-isopycnic mixing would prevent a state with stagnant deep water to be maintained, through the slow erosion of the stratification.

The results presented in this study correspond to an annual climatology based on the last $100 \mathrm{yr}$ (years 601 to 700 ).

\section{The general features of the Eastern Mediterranean Sea for the control climate}

For convenience, Fig. 2 names and locates the sub-basins of the Mediterranean, as well as the main straits.

\subsection{Near-surface circulation and deep water formation}

The circulation features of the Eastern Mediterranean Sea for the CTRL climate are illustrated in Fig. 3 by the near-surface currents field at $27 \mathrm{~m}$ depth. Two intense cyclonic gyres are represented in the Adriatic and in the North Levantine 


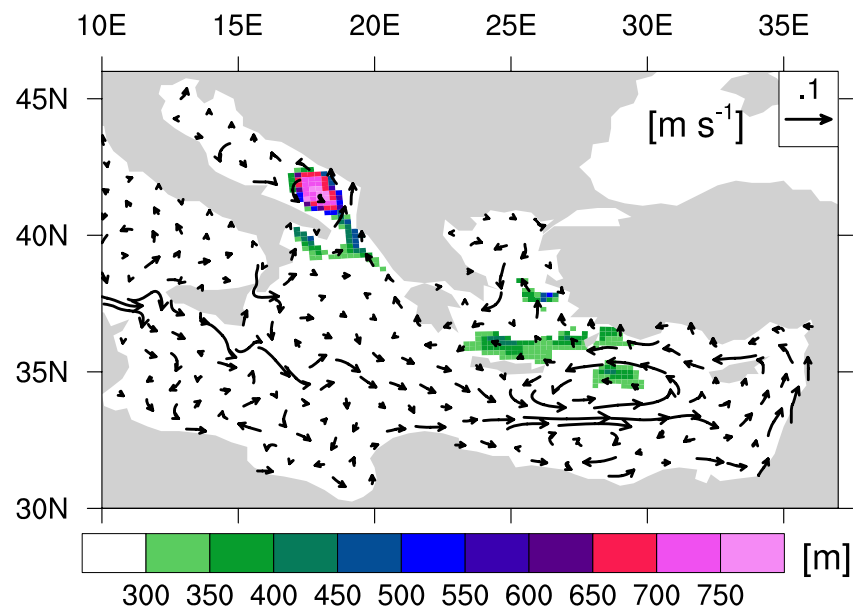

Fig. 3. Modelled March mixed layer depth (colours) and nearsurface currents field (arrows) at $27 \mathrm{~m}$ depth for CTRL. Only a subset of vectors has been plotted. The mixed layer depth is reached when the density difference between this depth and the surface exceeds $0.125 \mathrm{~kg} \mathrm{~m}^{-3}$. Note that such a calculation can only give an approximative estimate of the depth of the mixed layer.

basin (Rhodes Gyre). These gyres correspond to the location of dense water formation. Consistently with the description of the horizontal circulation structure summarized by Pinardi and Masetti (2000), the Atlantic-Ionian Stream coming from the Atlantic Ocean and entering through the Strait of Sicily into the central Ionian is well-simulated, as are the Mid-Mediterranean Jet flowing between Crete and the North African coast and the Asia Minor Current flowing along the Turkish coasts.

Linked to this general circulation, the winter mixed layer depth is an indicator widely used to assess the ability of a model to form the different Mediterranean water masses. In our model, the mixed layer depth is a purely diagnosed quantity which is calculated from a density criterion of $0.125 \mathrm{~kg} \mathrm{~m}^{-3}$, whose value has been originately motivated by the Levitus Atlas (Levitus, 1982). Such a calculation can only give an approximative estimate of the depth of the mixed layer.

Figure 3 shows that deep mixed layer patterns are modelled in the Adriatic, where the Adriatic Bottom Water (ABW) is formed and flows out of the Strait of Otranto, in the South Aegean Sea and in the North Levantine where the Levantine Intermediate Water (LIW) is formed. In the Ionian Sea, the mixing of transformed LIW with outflowing ABW forms the Eastern Mediterranean Deep Water (EMDW). The modelled mixed layer patterns are realistic and consistent with the climatology of D'Ortenzio et al. (2005) based on observations and calculated with a temperature difference criterion.

The strength of the Mediterranean thermohaline circulation (MTHC) is assessed with the zonal overturning stream function displayed in Fig. 4. Driven by salinity and tempera-

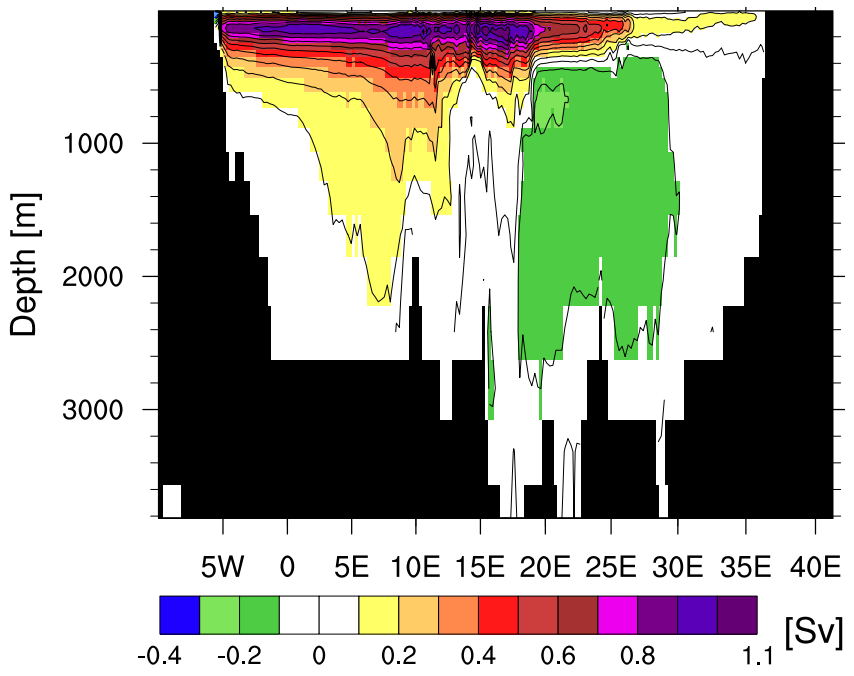

Fig. 4. Zonal overturning stream function integrated over the entire Mediterranean basin for the CTRL experiment. It has been calculated on the basis of a 100-yr mean velocity field.

ture differences, the MTHC is characterised by two main circulation cells. The first cell covers both the western and eastern basin, and has a clockwise circulation with modified Atlantic water travelling toward the east at the surface, and LIW travelling from the east to the west at intermediate depth. A maximum of $1.1 \mathrm{~Sv}$ is found at subsurface depth, between 100 and $200 \mathrm{~m}$ depth. Located in the eastern basin, the second cell shows a counterclockwise vertical circulation which is much weaker with a maximum of $0.2 \mathrm{~Sv}$. This cell corresponds to the circulation of EMDW toward the extreme east of the basin, this being compensated by a subsurface flow of LIW from the Northern Levantine toward the west.

The model simulates an averaged net water transport at Gibraltar of $0.051 \mathrm{~Sv}\left(1 \mathrm{~Sv}=10^{6} \mathrm{~m}^{3} \mathrm{~s}^{-1}\right)$, with a surface inflow of $0.84 \mathrm{~Sv}$ and a deep outflow of $0.79 \mathrm{~Sv}$. Those values are in agreement with observations by Bryden and Kinder (1991); Bryden et al. (1994); Tsimplis and Bryden (2000) and Baschek et al. (2001), who suggest values between 0.72 and $0.92 \mathrm{~Sv}$ for the inflow and between 0.68 and $0.88 \mathrm{~Sv}$ for the outflow. The modelled LIW transport at the Strait of Sicily from the eastern basin to the western basin occurs below $120 \mathrm{~m}$ depth and has a mean value around $1.04 \mathrm{~Sv}$ which is very close to the observed value of $1.1 \mathrm{~Sv}$ (Garzoli and Maillard, 1979; Astraldi et al., 1996).

\subsection{Surface temperature and salinity}

To assess the ability of the model to reproduce observed SST and SSS patterns, we compare our results from the CTRL simulation with the climatologies from WOA 1998 (Levitus et al., 1998) and MEDATLAS (MEDAR-Group, 2002). Because the temperature point in our model vertical discretization is at $6 \mathrm{~m}$ depth, we consider the climatological 


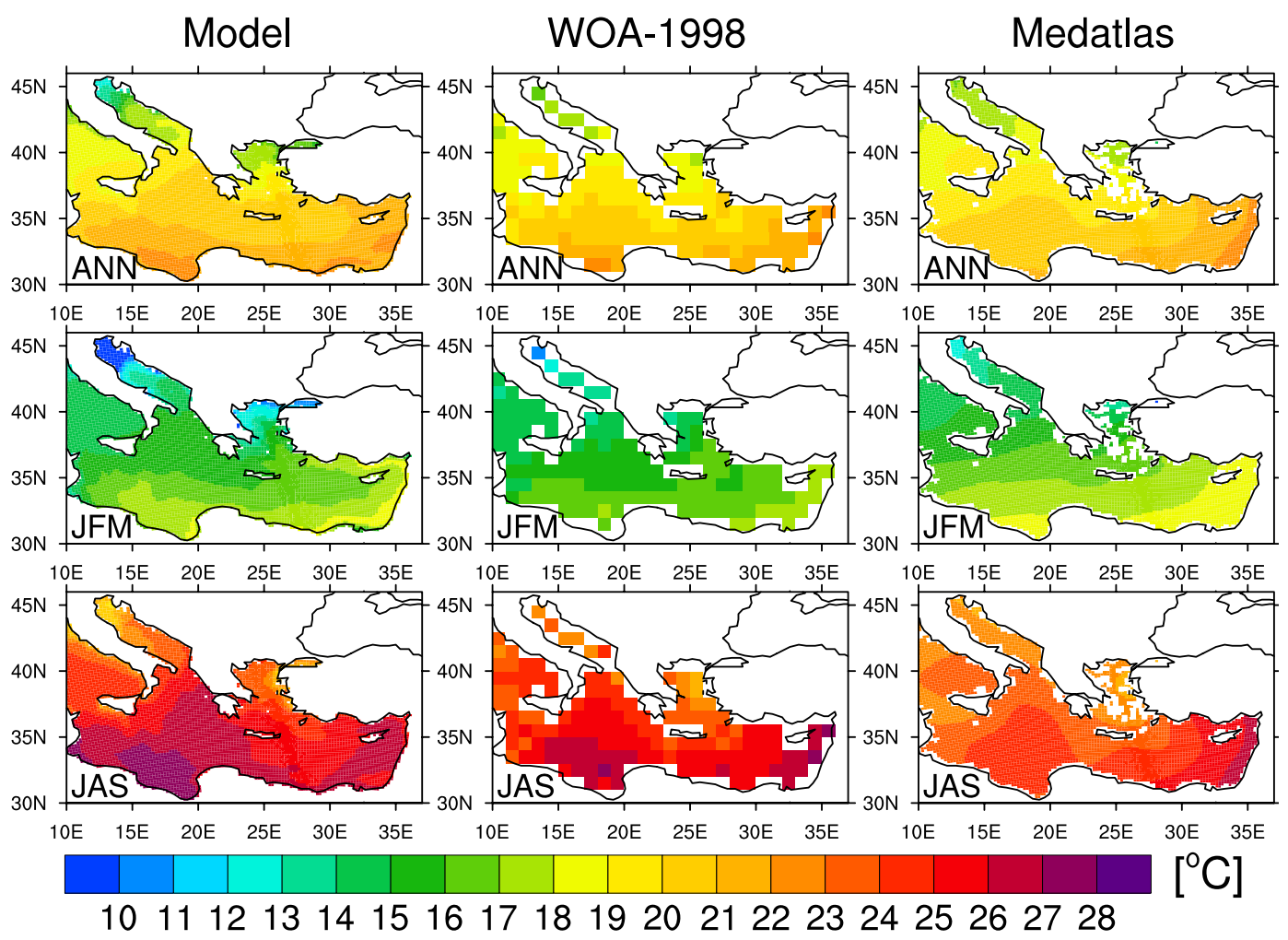

Fig. 5. Annual, winter (JFM) and summer (JAS) SSTs at $6 \mathrm{~m}$ depth for CTRL (left), World Ocean Atlas 1998 climatology (middle) and MEDATLAS climatology (right).

temperature interpolated to $6 \mathrm{~m}$ depth to make a consistent comparison.

Figure 5 shows the comparison between the modelled and both climatological SSTs. The model exhibits SST gradient from west to east and from north to south, consistently with the climatologies. For the annual mean as well as for winter (JFM) SSTs, the deviations remain below $1 \mathrm{~K}$. The winter modelled SST values are in between the values of both climatologies, MEDATLAS showing slightly warmer SST than WOA in the Levantine Sea and in the southern Ionian Sea. Both the Aegean and Adriatic Seas have too cold simulated temperatures during winter time. These regions are almost land-locked, with narrow connections to the wider part of the Eastern Mediterranean, through the Strait of Otranto for the Adriatic Sea and three straits of the Cretan Arc for the Aegean Sea. Small-scale atmospheric processes are acting over both areas, so that accurate wind patterns are difficult to simulate adequately at the resolution we are using. For summer (JAS), WOA displays SST 1 to $2 \mathrm{~K}$ warmer than MEDATLAS. The modelled summer SST shows warm biases in comparison with both climatologies. In the southern Ionian Sea and in the eastern Levantine Sea, biases up to $3 \mathrm{~K}$ are simulated by the model (in comparison with MEDATLAS, the coldest climatology). These biases could be due to the Atlantic-Ionian jet travelling slightly too far north in the model (compared to Pinardi and Masetti, 2000), thus, reduc- ing the import of cooler water from the western basin into the southern Ionian Sea.

Figure 6 displays the deviations of the annual mean modelled SSS from both MEDATLAS and WOA climatologies. The comparison of model results with each climatology exhibits similar discrepancies, which are found in the Levantine and in the Cretan region with a salty bias around $0.3 \mathrm{~g} \mathrm{~kg}^{-1}$. The fresh bias in the northern Aegean indicates that the model overestimates the freshwater input in this region. The northern part of the Adriatic Sea has a strong negative salinity anomaly corresponding to the fresh tongue from the Po river runoff that flows along the western coast. Nevertheless, the central and South Adriatic show a strong salty bias up to $0.5 \mathrm{~g} \mathrm{~kg}^{-1}$ which can be linked to the underestimation of the mean freshwater input from the Adriatic rivers as well as the overestimation of the penetration of salty Ionian water into the Adriatic. However, part of this discrepancy is probably artificial, as it can be attributed to the smoothing of the observational data, which has been introduced in the generation of the observational climatologies. Finally, the model has a positive salinity bias all along the North African coast. There are several contributors to this bias. First, this area has a warm SST bias (probably linked to the inability of the model to represent small scale atmospheric processes at the coasts, as explained before), this leads to a stronger evaporation and consequently higher salinities. Second, the regional 


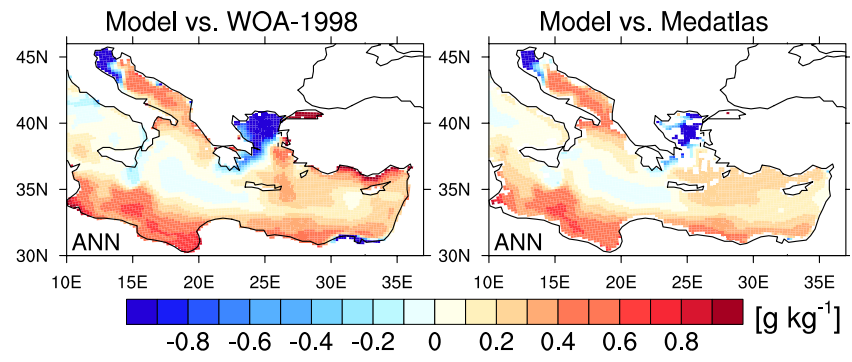

Fig. 6. Annual mean SSS deviations at $6 \mathrm{~m}$ depth. CTRL vs. World Ocean Atlas 1998 climatology (left) and CTRL vs. MEDATLAS climatology (right) are represented.

river discharge may be underestimated. Third, the AtlanticIonian jet, which brings fresher water to the eastern basin, is located slightly too far north in the model. Thus, the southern Ionian remains somewhat isolated and is not significantly impacted by this fresher current. Most of the discrepancies do not reflect the inadequacy of the model to correctly simulate consistent SSS, but they can be directly linked to some discrepancies in the freshwater components of our forcing, mainly the too low precipitation (explained hereafter) as well as missing river discharge. On average, this induces a mean positive salinity bias of $0.25 \mathrm{~g} \mathrm{~kg}^{-1}$ in the eastern basin.

\subsection{Water budget}

Table 1 summarizes the different components of the freshwater budget for the Mediterranean. The averaged precipitation prescribed over the Mediterranean Sea from the global model is only $0.59 \mathrm{~mm} \mathrm{~d}^{-1}$ and the averaged calculated evaporation is $2.83 \mathrm{~mm} \mathrm{~d}^{-1}$. The rivers contribute to the freshwater input by adding $0.35 \mathrm{~mm} \mathrm{~d}^{-1}$. The input from the rivers is close to the data from Ludwig et al. (2009), who indicate a value of $0.39 \mathrm{~mm} \mathrm{~d}^{-1}$. Nevertheless, the amount of prescribed precipitation is relatively low in comparison with both observations and reanalysis $\left(0.7 \mathrm{~mm} \mathrm{~d}^{-1}\right.$ in HOAPS, Andersson et al. (2007); and $1.07 \mathrm{~mm} \mathrm{~d}^{-1}$ in ERA-Interim Reanalysis, Simmons et al. (2007)). The interactively calculated evaporation is also lower than values from reanalysis $\left(3.34 \mathrm{~mm} \mathrm{~d}^{-1}\right.$ in ERA-Interim Reanalysis) and observations $\left(3.12 \mathrm{~mm} \mathrm{~d}^{-1}\right.$ in HOAPS).

The resulting water deficit of $1.89 \mathrm{~mm} \mathrm{~d}^{-1}$ is compensated by the positive net freshwater transport from the Black Sea into the Mediterranean through the Strait of the Dardanelles $\left(0.18 \mathrm{~mm} \mathrm{~d}^{-1}\right.$ or $\left.0.0055 \mathrm{~Sv}\right)$ and from the Atlantic Ocean through the Strait of Gibraltar $\left(1.71 \mathrm{~mm} \mathrm{~d}^{-1}\right.$ or $\left.0.051 \mathrm{~Sv}\right)$. The net water transport through both straits is consistent with the observations. Bryden et al. (1994), Bryden and Kinder (1991) and Béthoux (1979) suggest the values of $1.42 \mathrm{~mm} \mathrm{~d}^{-1}, 1.37-1.64 \mathrm{~mm} \mathrm{~d}^{-1}$ and $2.74 \mathrm{~mm} \mathrm{~d}^{-1}$, respectively, for the estimation of the net water transport at Gibraltar. Concerning the net water transport from the Black Sea through the Strait of the Dardanelles, the data from Stanev and Peneva (2002) indicate a value of $0.22 \mathrm{~mm} \mathrm{~d}^{-1}$.

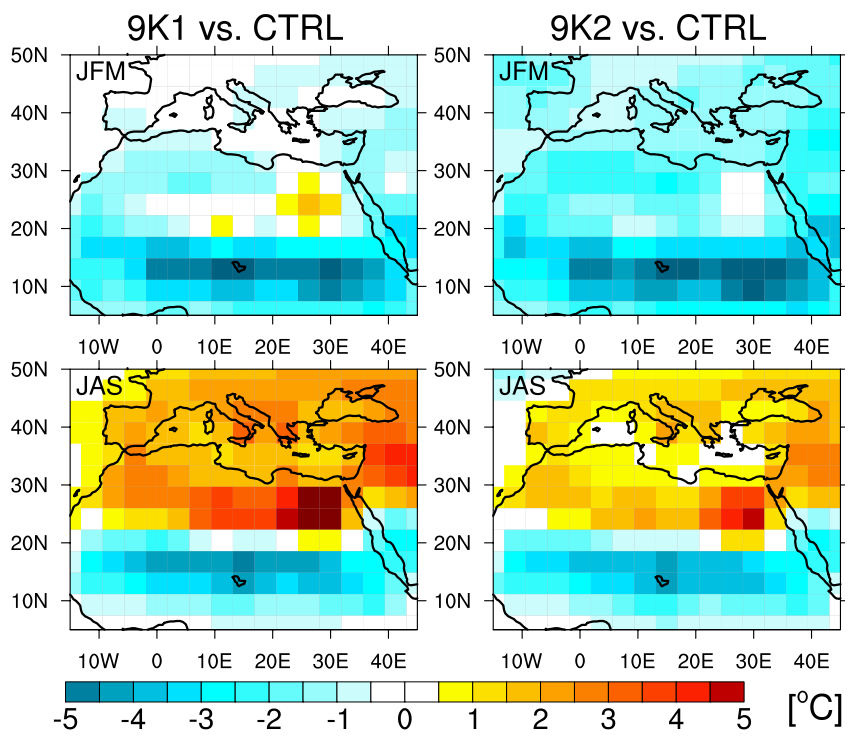

Fig. 7. Anomalies of 2-meter air temperature for winter (JFM) and summer (JAS) from global simulations, 9K1 vs. CTRL (left) and 9K2 vs. CTRL (right).

In Table 1, we also compare the mean values of each component of the water budget averaged for the full Mediterranean with those averaged for the eastern basin only (from the Strait of Sicily until the Bosphorus). This shows how much the eastern basin differs from the western in terms of $E-P$ balance. We observe that the mean precipitation rate in the eastern basin is around $20 \%$ lower than for the full basin, the mean river input is $6 \%$ lower and the mean evaporation is $6 \%$ higher. The Nile is responsible for $44 \%$ of the river input of the eastern basin.

\section{The Holocene Insolation Maximum}

\subsection{Stronger seasonal cycle}

In the HIM global simulations, the changes in the Earth's orbital parameters lead to stronger amplitude of the seasonal cycle of insolation. The averaged downward short wave radiation at the top of the atmosphere over the Mediterranean Sea is increased by about $15 \mathrm{~W} \mathrm{~m}^{-2}$ during the summer season and is decreased by about $15.5 \mathrm{~W} \mathrm{~m}^{-2}$ during the winter season for both $9 \mathrm{~K} 1$ and $9 \mathrm{~K} 2$ experiments in comparison with the CTRL experiment. This leads to an increased summer warming and an enhanced winter cooling as shown by the near-surface air temperature anomalies signal displayed in Fig. 7. The more realistic set up in $9 \mathrm{~K} 2$, with the decaying Laurentide ice sheet and lower atmospheric $p \mathrm{CO}_{2}$, leads to a generally slightly colder climate than in $9 \mathrm{~K} 1$. In 9K2, the summer warming is smaller and the winter cooling is stronger compared to the $9 \mathrm{~K} 1$ simulation. 
Table 1. Freshwater budget for the Mediterranean and the Eastern Mediterranean for CTRL, 9K1 and 9K2.

\begin{tabular}{|c|c|c|c|c|c|c|}
\hline \multirow[b]{2}{*}[\mathrm{mm}\mathrm{d}^{-1}]{} & \multicolumn{3}{|c|}{ Mediterranean } & \multicolumn{3}{|c|}{ Eastern Mediterranean } \\
\hline & CTRL & $9 \mathrm{~K} 1$ & $9 \mathrm{~K} 2$ & CTRL & $9 \mathrm{~K} 1$ & $9 \mathrm{~K} 2$ \\
\hline Precipitation $(P)$ & 0.59 & 0.66 & 0.60 & 0.51 & 0.58 & 0.52 \\
\hline Evaporation $(E)$ & 2.83 & 2.87 & 2.83 & 2.99 & 3.03 & 2.98 \\
\hline River runoff $(R)$ & 0.35 & 0.53 & 0.45 & 0.33 & 0.61 & 0.49 \\
\hline$P+R-E$ & -1.89 & -1.68 & -1.78 & -2.15 & -1.84 & -1.97 \\
\hline $\begin{array}{l}\text { Net water transport } \\
\text { at Gibraltar }\end{array}$ & 1.71 & 1.68 & 1.78 & & & \\
\hline $\begin{array}{l}\text { Net water transport } \\
\text { at Bosphorus }\end{array}$ & 0.18 & & & 0.28 & & \\
\hline \multicolumn{7}{|l|}{$\left[\mathrm{m}^{3} \mathrm{~s}^{-1}\right]$} \\
\hline River runoff (R) & 10443 & 15535 & 13070 & 6630 & 11697 & 9319 \\
\hline Nile runoff & 2930 & 7494 & 5401 & 2930 & 7494 & 5401 \\
\hline $\begin{array}{l}\text { Net water transport } \\
\text { at Gibraltar }\end{array}$ & 51000 & 49000 & 52000 & & & \\
\hline $\begin{array}{l}\text { Net water transport } \\
\text { at Bosphorus }\end{array}$ & 5621 & & & 5621 & & \\
\hline
\end{tabular}

In the global simulations, the increase in the amplitude of the seasonal cycle of solar forcing during the HIM is associated with an intensification of the Northern Hemisphere summer monsoon. The gradient of atmospheric pressure between land and sea being amplified, the monsoonal circulation is strengthened. The enhanced North African monsoon signal is well caught by the model and leads to an increased evaporation (Fig. 8). On the ocean grid points, the Mediterranean region is characterised by a precipitation increase in $9 \mathrm{~K} 1$, whereas this is only true for some part of the Eastern Mediterranean basin in 9K2. This increase in $P$ is related to the more southerly propagation of cyclones in winter. In summer, the increase in $P$ is related to an enhanced water recycling. The increased evaporation prevails on the ocean grid points, leading to negative $P-E$ anomalies, except for the eastern Levantine which shows a reduced evaporation (thus, positive $P-E$ anomalies) in both simulations (Fig. 8). The Nile has a larger water discharge for the HIM with runoff surplus of $4564 \mathrm{~m}^{3} \mathrm{~s}^{-1}$ for the $9 \mathrm{~K} 1$ simulation and $2471 \mathrm{~m}^{3} \mathrm{~s}^{-1}$ for the 9K2 simulation compared to the CTRL experiment.

Table 1 summarizes each component of the water budget from the ocean model (ocean grid points only), for the CTRL and the two HIM simulations. Values are averaged for (i) the entire Mediterranean and (ii) the Eastern Mediterranean. If we consider the entire Mediterranean, the precipitation remains almost constant for the 9K2 simulation, but we see an increase of $12 \%$ for the $9 \mathrm{~K} 1$ simulation. In av- erage, the evaporation is almost unchanged. The total riverine freshwater input is increased by more than $50 \%$ for the 9K1 simulation and more than $28 \%$ for the $9 \mathrm{~K} 2$ simulation. In both cases, the increase is mainly due to the enhanced discharge from the Nile river which is fed by the increased North African monsoon. If we consider the eastern basin only, the increase in precipitation is higher with a value of $14 \%$ for the 9K1 simulation and can be neglected for 9K2. The averaged changes in evaporation are small for both simulations. The freshwater input from the river runoff into the Eastern Mediterranean is almost doubled in the 9K1 simulation and enhanced by $48 \%$ in the $9 \mathrm{~K} 2$ simulation. In both cases the enhanced Nile runoff is the main contributor to this increase. Mainly because of the enhanced riverine input, the $P+R-E$ value over the Eastern Mediterranean increases slightly during the HIM.

In general, the freshwater budget does not show strong changes because the enhanced Nile runoff partially compensates the missing water from the Black Sea.

\subsection{Salinity, stratification and deep water formation}

As a consequence of the missing outflow from the Black Sea due to the closure of the Bosphorus in the HIM simulations, the salinity of the Aegean Sea increases in 9K1 and 9K2 (Fig. 9). This results in a shift of the location of intermediate water formation from the North Levantine/South 

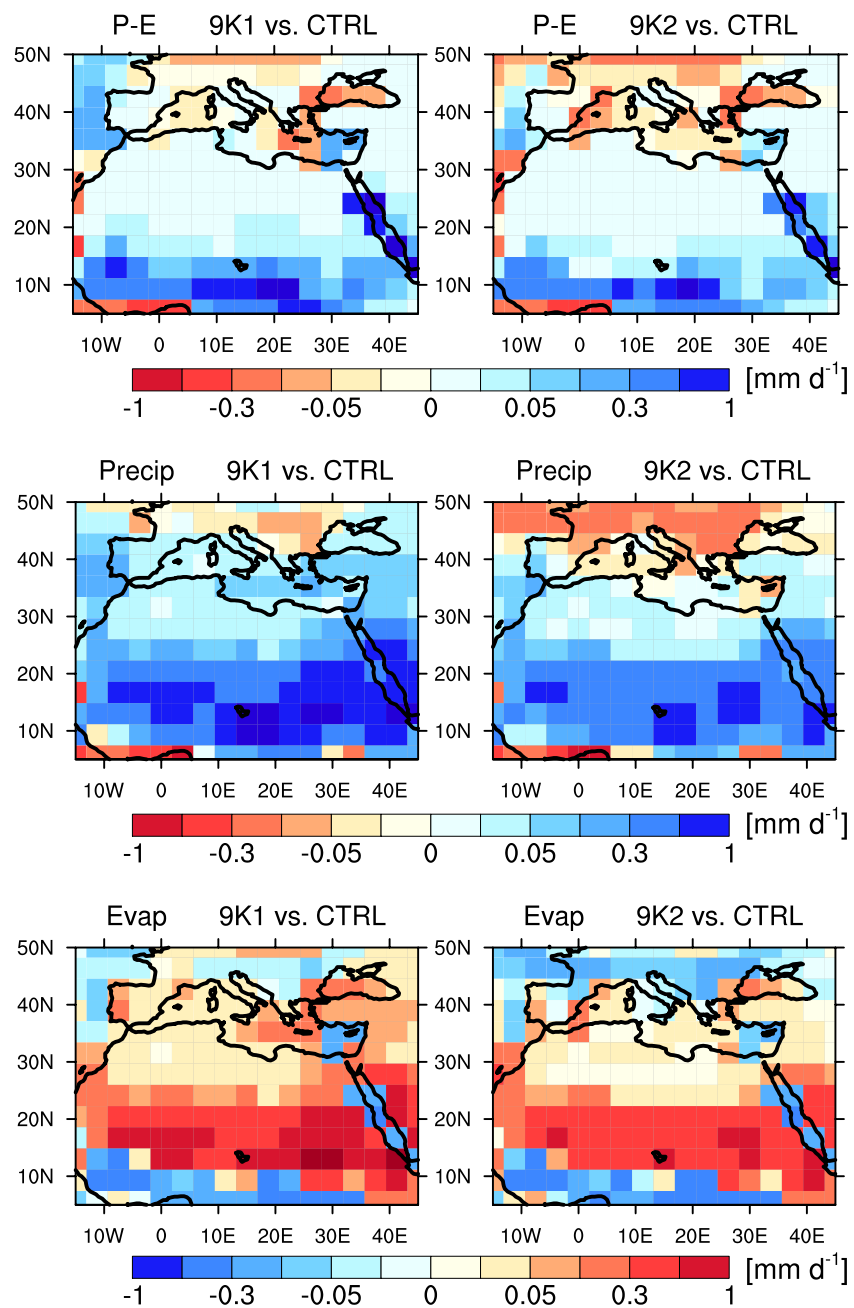

Fig. 8. Annual mean anomalies of $P-E, P$ and $E$ from global simulations, 9K1 vs. CTRL (left) and 9K2 vs. CTRL (right).

Aegean towards the North Aegean (Fig. 9). This confirms what has been recently suggested by the proxy-based study of Schmiedl et al. (2010), which implies a persistent deep water ventilation in the northern Aegean Sea during the HIM. In our simulations, the salty and relatively dense water formed in this region flows out of the Aegean Sea through the Strait of Antikithira and follows the western Greek coast towards the Adriatic. Along the trajectory following western Greece, a mixed layer pattern of intermediate depth appears due to the fact that the dense salty water flowing from the Aegean entrains the surrounding lighter water on its way to the Adriatic. During the HIM, the deep outflow of Mediterranean water through the Strait of Gibraltar decreases with values of 0.72 and $0.77 \mathrm{~Sv}$, respectively, for $9 \mathrm{~K} 1$ and $9 \mathrm{~K} 2$ (vs. $0.79 \mathrm{~Sv}$ in CTRL).

In both HIM simulations, the modelled SSSs averaged over the eastern basin are higher than in CTRL, with positive anomalies of $0.17 \mathrm{~g} \mathrm{~kg}^{-1}$ (9K1) and $0.48 \mathrm{~g} \mathrm{~kg}^{-1}$ (9K2).
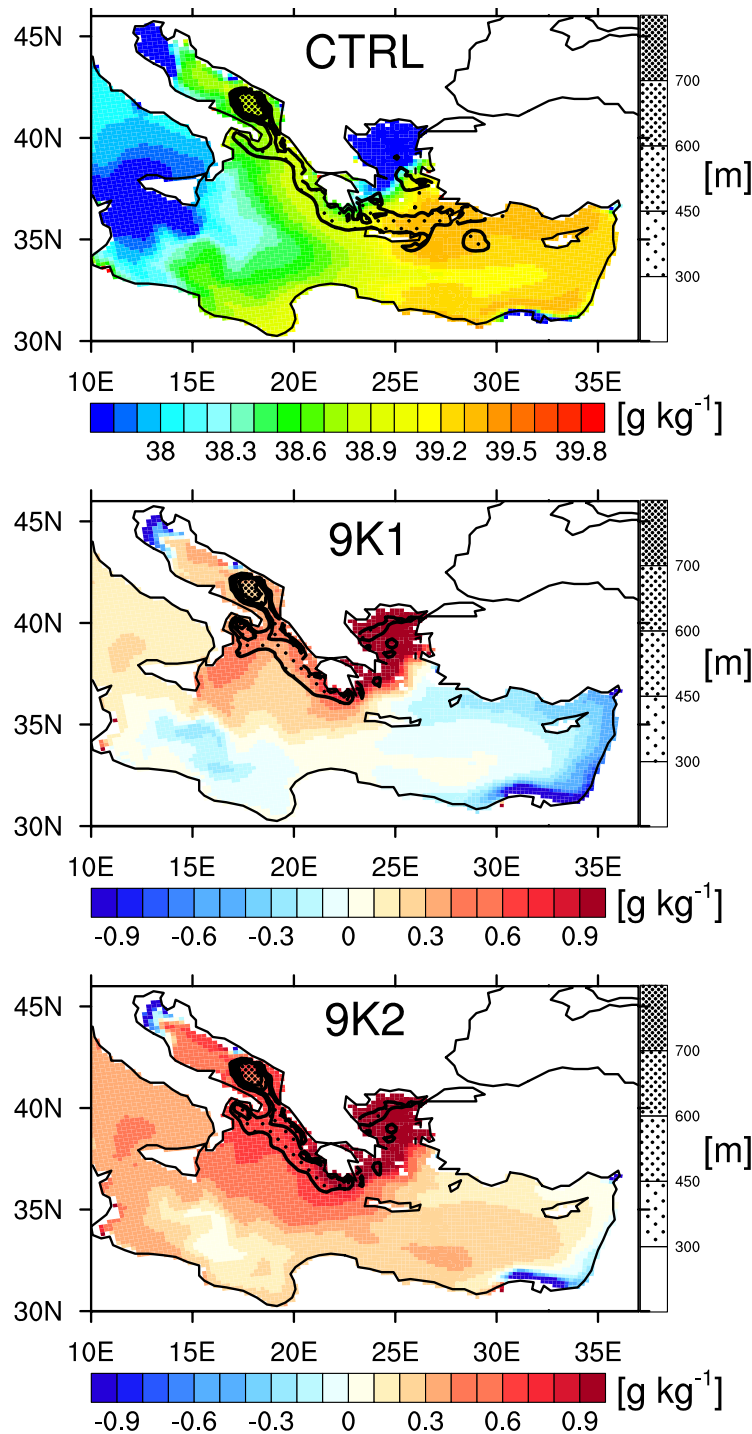

Fig. 9. Annual mean SSS (CTRL, top) and SSS anomalies vs. CTRL (9K1, middle; 9K2, bottom) at $6 \mathrm{~m}$ depth (colours). March mixed layer depth is overlaid as fill patterns.

The rough difference of $0.3 \mathrm{~g} \mathrm{~kg}^{-1}$ between $9 \mathrm{~K} 1$ and $9 \mathrm{~K} 2$ is mainly caused by changes in the properties of the inflowing Atlantic water. In 9K2, the salinity prescribed at the western Atlantic boundary is higher because the corresponding global simulation has a lower sea level, which is not the case in the $9 \mathrm{~K} 1$ global simulation. Acting in the opposite direction, the enhanced discharge of the Nile tends to reduce the salinity. The latter effect is stronger in $9 \mathrm{~K} 1$ than in $9 \mathrm{~K} 2$. Despite their differences in SSS anomalies, the modelled winter mixed layer depth patterns remain similar in both HIM simulations.

The simulated SSS anomalies display a signal which is not too far from the one reconstructed for $9 \mathrm{ka}$ BP. In the Tyrrhenian Sea, Kallel et al. (1997) reconstructed SSS around 
Table 2. Index of Stratification (IS, in $\mathrm{m}^{2} \mathrm{~s}^{-2}$ ).

\begin{tabular}{lrrr}
\hline & CTRL & 9K1 & 9K2 \\
\hline Adriatic & 0.95 & 1.00 & 0.98 \\
South Aegean & 1.07 & 1.27 & 1.27 \\
North Aegean & 1.25 & 0.92 & 0.89 \\
\hline
\end{tabular}

$1 \mathrm{~g} \mathrm{~kg}^{-1}$ saltier than today, the model simulates positive anomalies of 0.1 (9K1) and $0.35 \mathrm{~g} \mathrm{~kg}^{-1}$ (9K2). In the Ionian Sea, Emeis et al. (2000) reconstructed SSS anomalies $1 \mathrm{~g} \mathrm{~kg}^{-1}$ higher than present-day, the model exhibits SSS anomalies of +0.35 (9K1) and $+0.5 \mathrm{~g} \mathrm{~kg}^{-1}$ (9K2). Finally the SSS signal reconstructed in the Levantine by Emeis et al. (2000) is $2 \mathrm{~g} \mathrm{~kg}^{-1}$ fresher than today, whereas the model shows SSS anomalies of - 0.15 (9K1) and $+0.2 \mathrm{~g} \mathrm{~kg}^{-1}$ (9K2). The inconsistency between model and reconstruction in the Levantine is probably related to the Nile runoff which could be underestimated by the global model (particularly in the 9K2 simulation), thus leading to too salty SSS.

To assess the impact of the salinity changes on the ventilation of the deeper layers, we focus on the vertical stratification of the water column and calculate an Index of Stratification (IS) (in $\mathrm{m}^{2} \mathrm{~s}^{-2}$, see Beuvier et al., 2010; ?; Somot, 2005; Lascaratos, 1993). This index has been used in previous studies to investigate the preconditioning of the convection by looking at the changes in the vertical stratification. It corresponds to the loss of buoyancy required to induce a convection event up to the bottom of the sea. The lower the index, the more likely the convection to occur is. IS is calculated on a 100 -yr mean basis, for each model grid point $(i, j)$ using the following formula:

$\operatorname{IS}\left(i, j, h_{\mathrm{bot}}\right)=\int_{0}^{h_{\mathrm{bot}}} N^{2}(i, j, z) z \mathrm{~d} z$

where $z$ is the depth, $h_{\text {bot }}$ is the depth at the bottom and $N$ is the local Brunt-Vaisala frequency: $N^{2}=\frac{g}{\rho} \frac{\partial \rho}{\partial z}$.

Table 2 compiles IS values averaged over the main convective areas for the three simulations. In the Adriatic, the most active location for deep water formation, low IS values are displayed for the three simulations, reflecting a weak stratification. From these similarities, we infer that the deep water production in the Adriatic remains identical during the HIM with formation rates comparable to CTRL. This happens because the changes in surface salinity have reached the deeper layers and the state has became quasi-stationary with a stable density gradient similar to CTRL. During the HIM, both past experiments simulate a decreased IS in the North Aegean and an increased IS in the South Aegean in comparison with CTRL, consistently with the shift of winter mixed layer depth pattern from the south to the north displayed in Fig. 9.

We, thus, obtain 3 simulations, each representing a wellventilated state. Winter convection occurs in different sub-

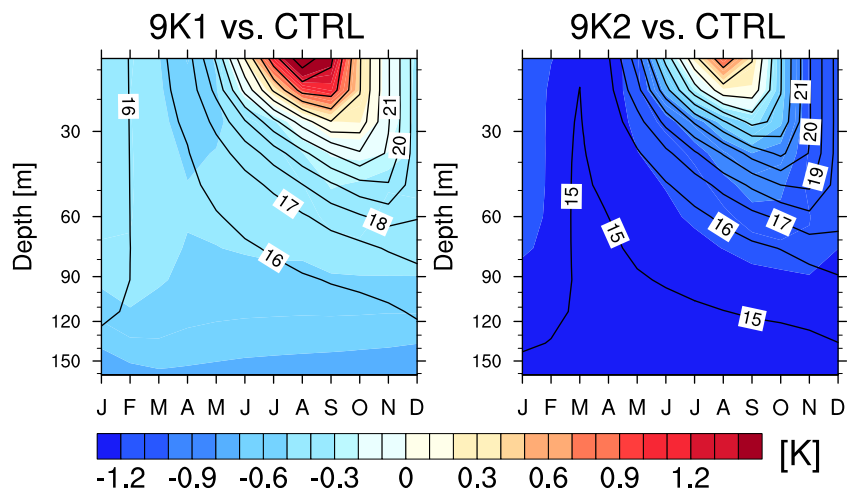

Fig. 10. Anomalies in monthly seasonal cycle of upper ocean temperature averaged over the Eastern Mediterranean, 9K1 vs. CTRL (left) and 9K2 vs. CTRL (right); isolines represent the absolute values in ${ }^{\circ} \mathrm{C}$ for $9 \mathrm{~K} 1$ (left) and 9K2 (right).

basins to form intermediate and deep water. Dense water formation takes place in the Adriatic, the South Aegean and the Northeastern Levantine in CTRL. In the HIM simulations, dense waters are formed in the Adriatic and the North Aegean. Despite these small shifts of winter mixed layer depth patterns between past and present, the HIM zonal overturning stream function remains almost identical, with a deep counter-clockwise cell in the eastern Mediterranean, displaying a maximum value of $0.2 \mathrm{~Sv}$, as seen in CTRL (Fig. 4). These simulated past climate states aim at representing a stable and stationary environment before entering into the transition phase which triggered the sapropels through weakened/prevented ventilation of the deep water.

\subsection{The upper-ocean temperature}

\subsubsection{Seasonal cycle}

As a direct effect of the changes in incoming short wave radiation at the surface, an increase in the amplitude of the seasonal cycle of the water temperature (Fig. 10) is simulated. The enhanced cooling during winter spreads over the entire water column through mixing and convective processes. The enhanced seasonal cycle leads to warmer surface temperatures in both $9 \mathrm{~K}$ simulations in summer. During spring and summer, stable stratification prevents a deep penetration of the warming signal. The region with temperatures warmer than in the CTRL run is, thus, restricted to the upper 30 and $20 \mathrm{~m}$, respectively, for the $9 \mathrm{~K} 1$ and $9 \mathrm{~K} 2$ simulations. Because the $9 \mathrm{~K} 1$ simulation is generally warmer than the $9 \mathrm{~K} 2$ simulation (the latter being colder due to the presence of rest of the Laurentide ice sheet and reduced atmospheric $p \mathrm{CO}_{2}$ in $9 \mathrm{~K} 2$ ), the summer warming relative to the CTRL run is more pronounced (up to $1.5 \mathrm{~K}$ for the surface water of the $9 \mathrm{~K} 1 \mathrm{ex}$ periment vs. $0.8 \mathrm{~K}$ for $9 \mathrm{~K} 2$ ) and spreads slightly deeper than for the $9 \mathrm{~K} 2$. Below, the water shows cold anomalies during summer, which is a remainder from the cold winter signal. 


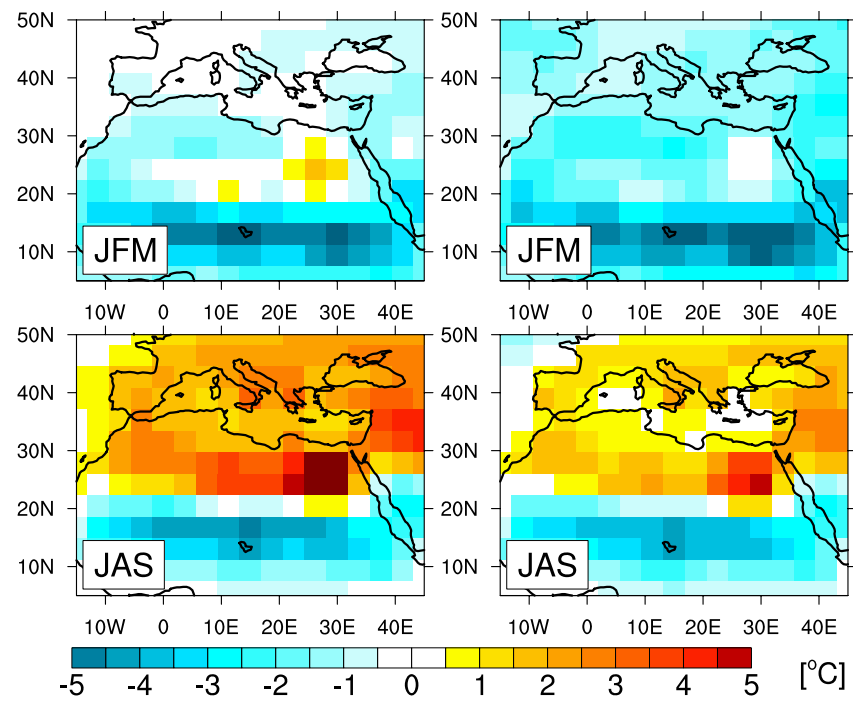

Fig. 11. Anomalies of summer (JAS) temperature at different depth levels, 9K1 vs. CTRL (left column) and 9K2 vs. CTRL (right column).

\subsubsection{The western Levantine subsurface warming pattern}

In this section, we analyse the patterns of the spread of the surface summer warming signal into the subsurface layers. Figure 11 displays the anomalies between $9 \mathrm{~K} 1 / 9 \mathrm{~K} 2$ and the CTRL, for $6 \mathrm{~m}$ depth (the modelled SST), $17 \mathrm{~m}$ depth and $27 \mathrm{~m}$ depth. The surface warming is relatively homogeneous for both paleo-simulations, but the subsurface temperature anomaly signal shows strong regional contrasts with a welldefined pattern. At a $17 \mathrm{~m}$ depth, the region around Crete and the western Levantine still show a warming signal, whereas the central Ionian, the Tyrrhenian and, only for 9K1, the eastern Levantine, experience a cooling. At a $27 \mathrm{~m}$ depth, cooling is mainly observed over the Eastern Mediterranean, but is strongly reduced around Crete and western Levantine, and even absent in the $9 \mathrm{~K} 1$ simulation.

The pattern of subsurface temperature anomalies is quite similar to the present-day pattern of subsurface spread of the summer SST in the Eastern Mediterranean (Fig. 12). The model shows weaker vertical gradients of the near-surface temperature in the western Levantine (and, thus, a deeper penetration of the summer warming signal) than in the eastern Levantine and the Ionian; the same pattern is also obvious in the MEDATLAS climatology.

The reduced vertical near-surface temperature gradient in the western Levantine is caused by the Etesian winds. The Etesian winds are dry northerly winds blowing over the Aegean Sea and the Levantine Sea from about mid-May to mid-September, mainly because of the monsoon effect leading to a thermal low pressure trough over Turkey, with higher pressure over southern Balkans; and the passage of cold fronts over the Balkans and the associated cold-air circula-

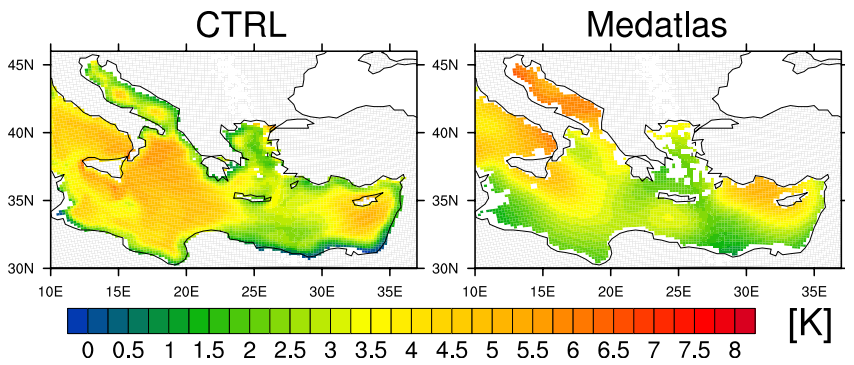

Fig. 12. Summer (JAS) temperature difference between 6 and $27 \mathrm{~m}$ of depth, for CTRL and MEDATLAS climatology.

tion behind them (e.g. Meteorological-Office, 1962; Brody and Nestor, 1985). In the model derived forcing used for CTRL, Etesian winds are acting from mid-May until midOctober (Fig. 13, black line) and are essentially a north-south blowing wind (Figs. 13 and 14). The westward Ekman transport induced by this wind pattern involves the upwelling of cold subsurface water in the eastern Levantine (resulting in a strong vertical near-surface temperature gradient) and downwelling of warm surface water west of the core of the Etesian winds with a reduced vertical near-surface temperature gradient. As an example, the vertical velocities and the associated subsurface heating rates are displayed in Fig. 15. The westward Ekman transport leads to a substantial heat transport from the eastern to the western Levantine. This becomes evident when comparing the atmospheric heat input with the actually observed changes in ocean heat content for the period from May to September, when the Etesian winds are present (Fig. 16, left). In the western Levantine, an additional heat source of up to $60 \mathrm{~W} \mathrm{~m}^{-2}$ working for 5 months is required to explain the changes in ocean temperature. In the eastern Levantine, a similar heat sink is required (up to $65 \mathrm{~W} \mathrm{~m}^{-2}$ ). In the centres of action, these heat source/sink correspond to more than $40 \%$ of the atmospheric heat input for this time of the year. The obvious connections are the westward Ekman transport of warm surface water and the compensation flow of colder subsurface water. This pattern is restricted to the period, when the Etesian winds are blowing. In the other months, westerly winds are prevailing. The annual mean climatological net air-sea heat exchange shows only a very weak annual mean heat loss in the western Levantine (Fig. S1 in the Supplement), indicating that the heat "piracy" of the western Levantine is restricted to late spring and summer. In the other months of the year, the western Levantine is actually exporting heat.

In order to determine, whether the summer heat piracy is a model artefact, we performed the same calculation using net atmospheric heat input from the ERA-Interim Reanalysis averaged over the years 1989-2005 (Berrisford et al., 2009) and the ocean heat content changes calculated from the MEDATLAS temperatures (Fig. 16, right). The results show an even stronger heat piracy (up to $150 \mathrm{~W} \mathrm{~m}^{-2}$ ) around Crete 

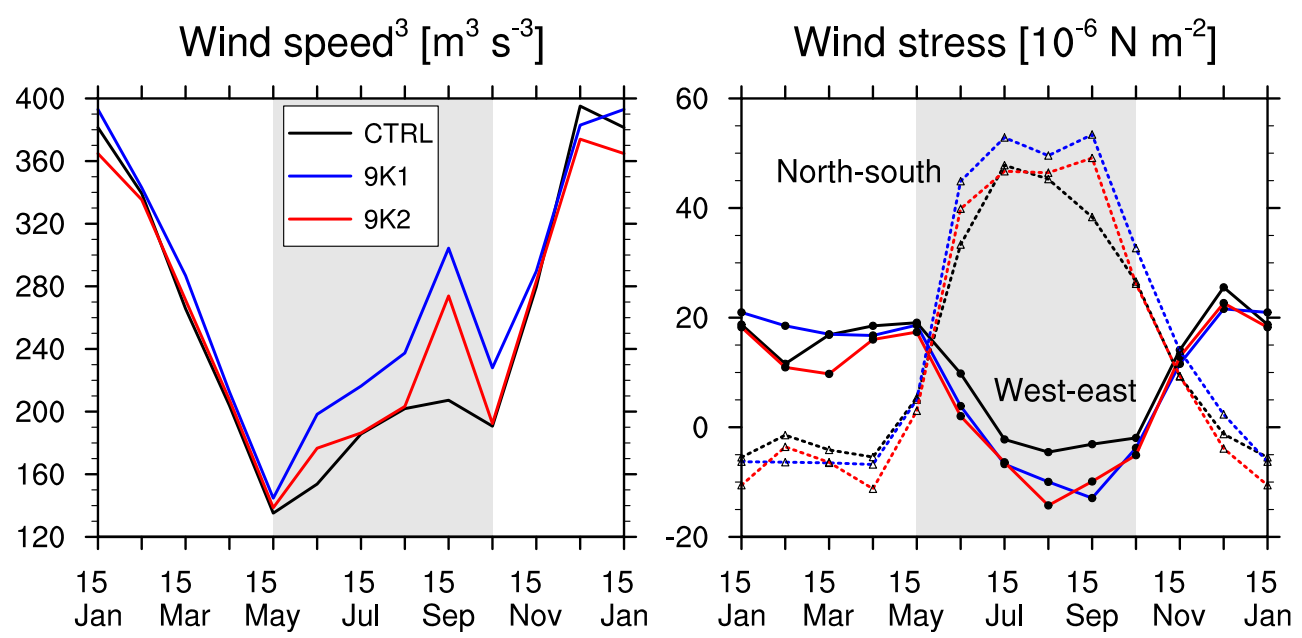

Fig. 13. Monthly climatology of wind components averaged over the Aegean/West Levantine regions for CTRL (black), 9K1 (blue) and 9K2 (red). Left panel shows 10-m wind speed cubed, the cubed value is considered because it is proportional to mixing strength. Right panel shows both west-east and north-south wind stress components. The shading represents the time period, when modelled Etesian winds are active.

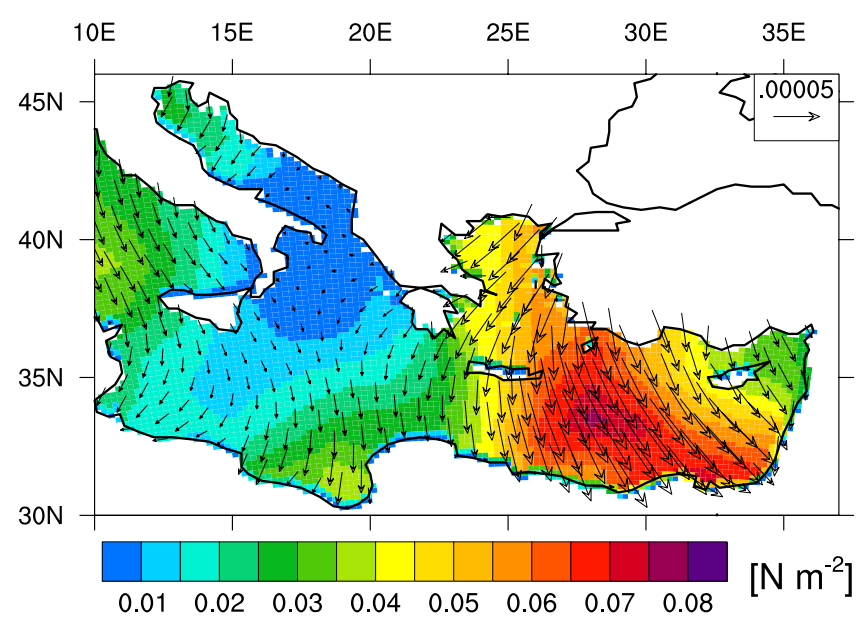

Fig. 14. Mean summer (JAS) wind stress for CTRL.

and in the southeastern Levantine. Additional simulations performed with our ocean model forced with ERA-Interim derived atmospheric forcing have produced similar results (not shown). The difference between modelled and observation derived-estimates can be explained by differences in the Etesian winds. The Etesian winds derived from the global model are essentially blowing from the north (Figs. 13 and 14). In the present-day observations, they also have a westerly component over the Levantine, thus, causing the westeast dipole of the model to be somewhat rotated with the strongest part of the upwelling shifted more to the southeast, and the strongest part of the downwelling shifted more to the south. The observed Etesian winds are also slightly stronger, which explains the stronger heat piracy in the observationbased estimate.

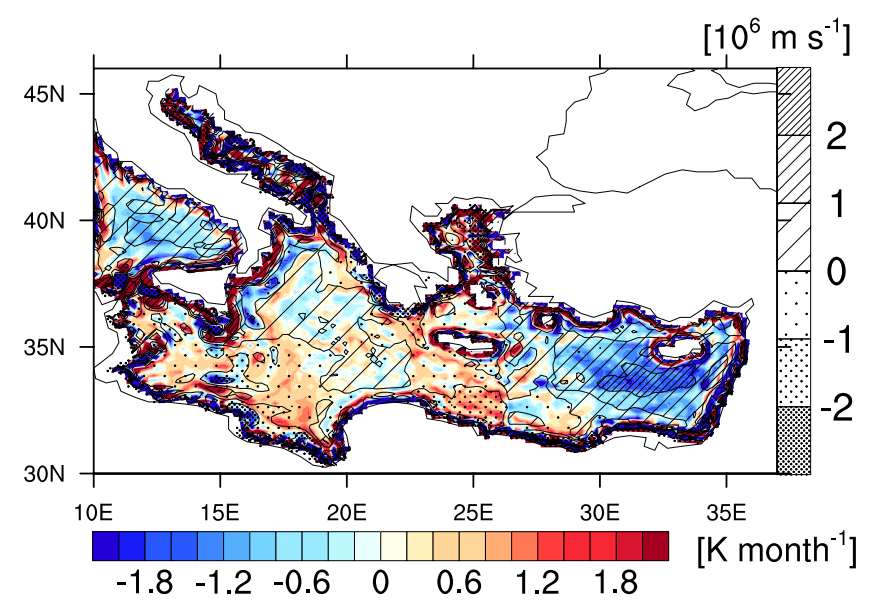

Fig. 15. Temperature change through vertical advection averaged between 12 and $42 \mathrm{~m}$ of depth (colours) and vertical velocities (fill patterns, positive values for upward velocities) in July for CTRL.

During the HIM, the amplified seasonal cycle of surface temperature (which is a direct effect of the insolation forcing) enhances the vertical gradients in near-surface ocean temperature. Together with the Ekman-induced circulation, this stronger seasonality of the insolation cycle could explain the pattern of subsurface temperature changes displayed by the anomalies 9K vs. CTRL (Fig. 11). In the upwelling region of eastern Levantine, colder subsurface water is upwelled, in the western Levantine warmer surface water is downwelled, thus, causing a positive anomaly of subsurface temperatures. Additionally, the modelled Etesian winds are found to be increased for both HIM experiments (Fig. 13): a further strengthening of the temperature dipole is, thus, expected through enhanced Ekman transport. 


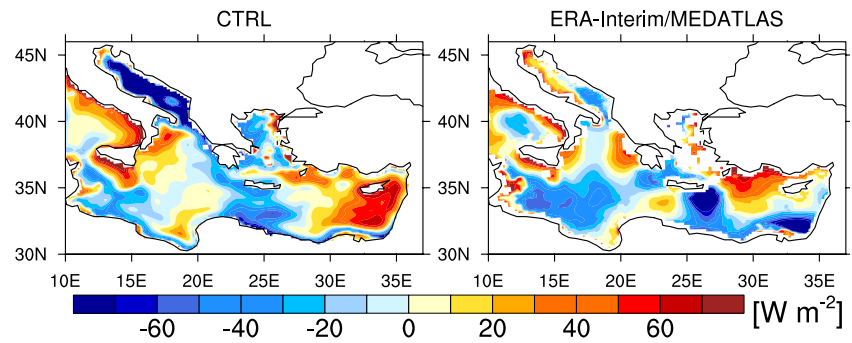

Fig. 16. Difference between the net atmospheric heat input and changes in ocean heat content from 1 May until 30 September. Left panel shows CTRL. Right panel shows differences between net atmospheric heat input from ERA-Interim Reanalysis (averaged over 1989/2005) and changes in ocean heat content from MEDATLAS climatology. Positive values indicate that the atmospheric input is higher than the temperature change in the water column, reflecting an export of heat from this region. Negative values reflect a heat accumulation.

In the following, the respective contributions of increased Etesian winds and enhanced seasonal cycle of insolation, to the subsurface temperature anomaly in the Cretan and south Levantine regions are analysed. For this purpose, two different 100 -yr sensitivity experiments are set up, all starting in year 600 of experiment $9 \mathrm{~K} 2$ :

- 9K2-W0 uses the same setup as the 9K2 simulation, but both wind speed and wind stress from CTRL (weaker Etesian winds) are prescribed. With this simulation, the effect from the "full" wind (speed and stress) on the 9K2 climate can be assessed when compared with $9 \mathrm{~K} 2$, and the effect of the increased thermal forcing alone can be assessed when compared to CTRL.

- CTRL-W9 is similar to CTRL simulation, but we prescribe both wind speed and wind stress from the 9K2 experiment (enhanced Etesian winds). This simulation enlightens the effect of the "full" wind signal (speed and stress) on the CTRL climate when compared with CTRL.

Figure 17 displays the contribution of different factors to temperature anomalies at different levels of the subsurface. Factors analysed are (i) the enhanced insolation forcing (9K2-W0 vs. CTRL), (ii) the increased Etesian winds on CTRL climate (CTRL-W9 vs. CTRL), and (iii) the increased Etesian winds on 9K2 climate (9K2 vs. 9K2-W0). Separate contributions are compared to the total effect from both increased winds and enhanced seasonal cycle of insolation (9K2 vs. CTRL).

The pure effect of the insolation in the $9 \mathrm{~K} 2$ simulation is dominant in the first model layer $(0-12 \mathrm{~m})$, and is responsible for a mean warming of $0.5 \mathrm{~K}$ (Fig. 17a). The contribution of enhanced winds induces a mean cold bias of $0.3 \mathrm{~K}$ on a CTRL climate (Fig. 17b) and $0.2 \mathrm{~K}$ on a $9 \mathrm{~K} 2$ climate (Fig. 17c). The wind-induced cooling is almost entirely a consequence of the enhanced wind speed which induces a stronger mixing at the top of the water column; this leads to stronger heat transfer from the sea surface toward subsurface, explaining the cold anomalies in the first ocean layer. The wind stress effect is small at the surface.

In the second layer $(12-22 \mathrm{~m})$, the insolation effect is strongly reduced with a warming around $0.2 \mathrm{~K}$ in the Cretan and southwestern Levantine regions and a cooling in eastern Levantine (Fig. 17e). These patterns are expected in this case, which combines enhanced summer insolation signal and present-day winds: the water downwelled in southwestern Levantine is warmer, leading to warmer pattern, and the subsurface water upwelled in eastern Levantine is colder, leading to cooler pattern. In this second layer, the main effect of stronger Etesian winds is still a cooling (Fig. 17f and $17 \mathrm{~g}$ ), however, a warming up to $0.2 \mathrm{~K}$ becomes noticeable in the south Levantine area on 9K2 climate (Fig. 17g).

From the third ocean layer $(22-32 \mathrm{~m})$ toward a greater depth, the remaining cooling from the winter is prevailing, explaining the cold anomalies displayed for the insolation effect (Fig. 17i and $17 \mathrm{~m}$ ). The effect from the increased wind becomes strong from $22 \mathrm{~m}$ on: on CTRL climate, southwestern Levantine shows warm anomalies up to $0.5 \mathrm{~K}$ in $22-32 \mathrm{~m}$ layer (Fig. 17j) and up to $0.8 \mathrm{~K}$ in $32-42 \mathrm{~m}$ layer, whereas the eastern Levantine cooling reached the value of $0.6 \mathrm{~K}$ in both layer. On 9K2 climate, the warming induced by increased winds in southwestern Levantine is $0.2 \mathrm{~K}$ stronger than on CTRL climate (Fig. 17k vs. 17j). This warm/cold dipole is triggered by the enhanced wind stress which leads to enhanced Ekman transport, namely stronger downwelling of surface warm water in southwestern Levantine and stronger upwelling of deeper cold water in eastern Levantine. Both patterns persist down to a $250 \mathrm{~m}$ depth. The increased wind speed is responsible for warm anomalies southeast of Crete in the layer $22-32 \mathrm{~m}$, where heat is gained through higher transfer to subsurface.

In general the wind effects become stronger when acting on a temperature distribution with enhanced vertical gradients. This becomes obvious when comparing the respective panels with wind effects on CTRL and 9K2 basis state. Thus, the nonlinear effects between the two mechanisms (stronger seasonal cycle and stronger Etesian winds) are amplifying the temperature signal.

When all effects are combined, the total results to a subsurface warming pattern around Crete and in southwestern Levantine in the 12-22 layer (Fig. 17h). The warming around Crete vanishes for the 22-32 m layer (Fig. 171), because of the prevailing cooling from the insolation signal (Fig. 17i). Only the warming in southwestern Levantine (induced by enhanced downwelling of warm water) is strong enough to prevail in the layer 22-32 m (Fig. 171).

From this analysis, we conclude that general anomalous heat accumulation happens in the region south of Crete for both CTRL (Fig. 16) and paleo-simulations in summer, and can be attributed to Ekman transport. However, during the 


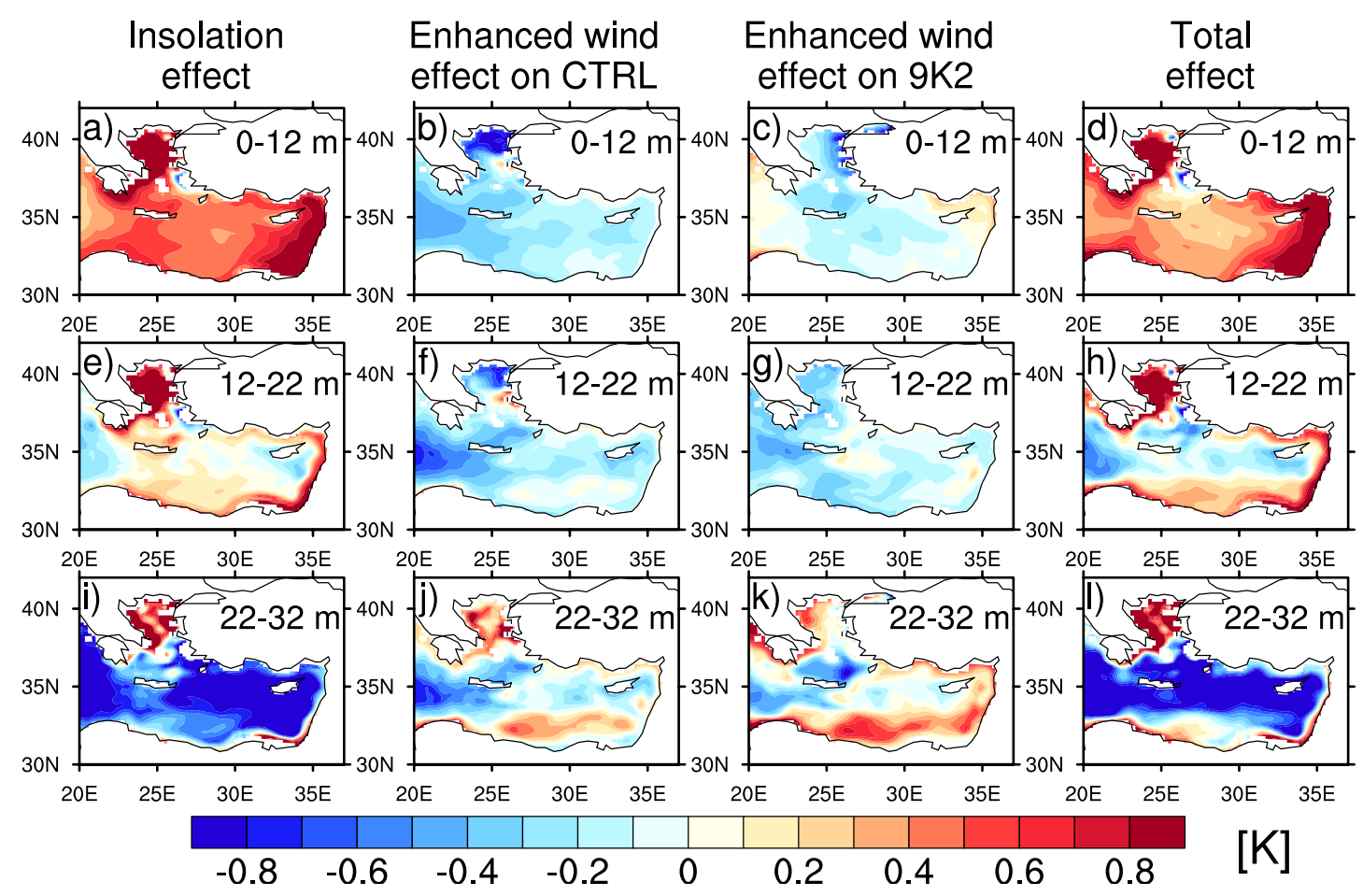

Fig. 17. Anomalies of temperature for different model depth layers for summer (JAS). The columns show the isolated effect of insolation forcing (9K2-W0 vs. CTRL), enhanced Etesian winds on CTRL climate (CTRL-W9 vs. CTRL) and on 9K2 climate (9K2 vs. 9K2-W0), as well as the total effect of both factors (9K2 vs. CTRL).

HIM, the combination of (i) enhanced downwelling in southwestern Levantine, (ii) enhanced mixing around Crete; both related to increased Etesian winds; and (iii) enhanced thermal forcing, are driving together stronger surface heat transfer to the subsurface during summer in the Cretan/southwestern Levantine region and are, thus, responsible for the simulated warm subsurface anomaly pattern.

\subsection{Comparison to proxy data}

\subsubsection{The SST reconstructions}

The transfer function used to reconstruct the paleo-SST is based on census counts of 23 species of planktonic foraminiferal species in 274 core tops, 145 from the Mediterranean and 129 from the Atlantic (Hayes et al., 2005). The data are calibrated to seasonal (JFM and JAS) and annual mean SST values at $10 \mathrm{~m}$ water depth from the observational dataset WOA (Levitus et al., 1998). The transfer function method based on "artificial neural networks" is described in Hayes et al. (2005).

Based on ${ }^{14} \mathrm{C}$ data, oxygen isotope stratigraphy, biostratigraphy or a combination of those, the Holocene Insolation Maximum interval has been identified in 33 Mediterranean sediment cores as an interval between approximately 9.5 and $8.5 \mathrm{ka}$ BP. Only samples occurring within this interval, as identified by the individual age models, were considered.
Faunal counts were collated with the same procedure as for the core-top samples. SST reconstructions were averaged throughout each Holocene Insolation Maximum Interval for each core.

The full data and discussion of the proxy resulted are presented in a companion paper by Kucera et al. (2011).

\subsubsection{SST model-proxy comparison}

In this section, we compare the SST modelled in 9K1 and 9K2 with the SST reconstructed from foraminifera for 9.5$8.5 \mathrm{ka}$ BP. We first consider absolute values and analyse annual, summer (JAS) and winter (JFM) temperatures.

Figure 18 displays, for each experiment, the fit between the SST reconstructions and the modelled SST at each core location; for annual mean, winter (JFM) and summer (JAS). In general, the 9K1 simulation, which only considers the change in solar forcing, yields too warm SST in comparison with the reconstructions. In contrast, the SST predicted by the model in the $9 \mathrm{~K} 2$ simulation show a better match with the reconstructions because the $9 \mathrm{~K} 2$ simulation also takes into account the cooling effect of the glaciers and the reduced atmospheric $\mathrm{CO}_{2}$ concentration, which lead to SST around $1 \mathrm{~K}$ colder than for the 9K1 simulation. The model-data discrepancies of the 9K1 simulation are mainly located in the central Ionian, with a warm SST bias of $1 \mathrm{~K}$ for annual mean and $3 \mathrm{~K}$ for summer (Fig. S2 in the Supplement). As for the CTRL 

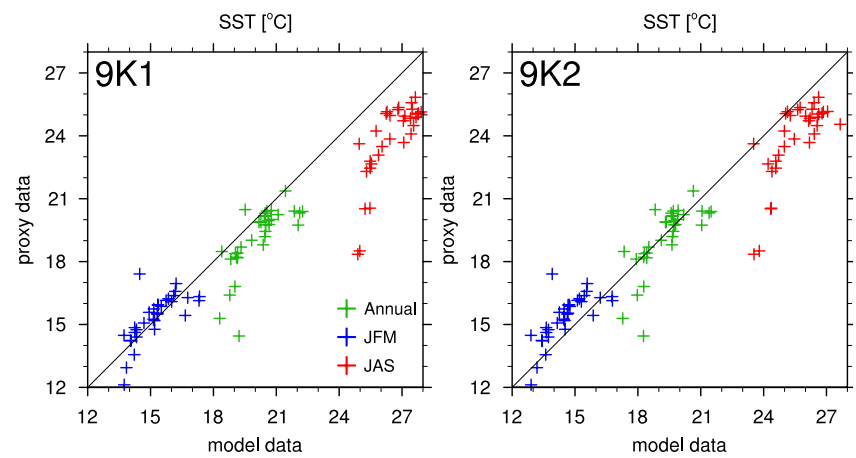

Fig. 18. Comparison of modelled SST with SST reconstructed from proxy data (Kucera et al., 2011) for 9K1 (left) and 9K2 (right). Annual mean, winter (JFM) and summer (JAS) are considered.

simulation, this bias may be linked to the Atlantic-Ionian jet travelling too far north in the model.

The two strongest deviations displayed in Fig. 18 refer to data located in the Adriatic and in the Aegean (Fig. S2 in the Supplement). These two regions are difficult to simulate at our resolution due to their size and small-scale processes acting over these areas, among these are katabatic winds, which are not resolved adequately by the coarse global model. This may explain the strong disagreement encountered in these locations with discrepancies up to $6 \mathrm{~K}$ and $5 \mathrm{~K}$ in summer, respectively, for 9K1 and 9K2 (Fig. S2 in the Supplement). Furthermore, the two temperature reconstructions available for the Adriatic differ strongly so that it is difficult to extract a clear signal from the observations for this region. For the two simulations, the modelled SST fall between both reconstructed SST values. The simulated winter SST matches well with the reconstructed signal (Fig. 18, blue): the biases do not exceed $1 \mathrm{~K}$ except for the Aegean. The major disagreement between model and proxy data is restricted to summer SST (Fig. 18, red): both HIM experiments show a warm bias with summer SST errors in excess of $3 \mathrm{~K}$ in average for the 9K1 simulation and $2 \mathrm{~K}$ for the $9 \mathrm{~K} 2$ simulation. Again, except for the enclosed Aegean and Adriatic Seas, the major discrepancies are found in the central Ionian and in the Tyrrhenian Sea (Fig. S2 in the Supplement).

To evaluate how model and reconstructions depict differences between the HIM and the present-day, we compare the 9K1/9K2 simulations with the CTRL simulation, and the SST reconstructed for the time slice 9.5-8.5 ka BP with pre-1998 instrumental mean SST. The differences allow us to check the ability of the model to reproduce the changes between the HIM and the present-day ocean state, without being affected by the internal model discrepancies that may have an impact on the absolute values. The reconstructed SST anomalies (Fig. 19) reveal strong spatial patterns of the signal. The annual and summer reconstructed SST anomalies (Fig. 19, 1st and 3rd rows) show a strong warming around the Cretan region and a cooling of the middle Ionian, the
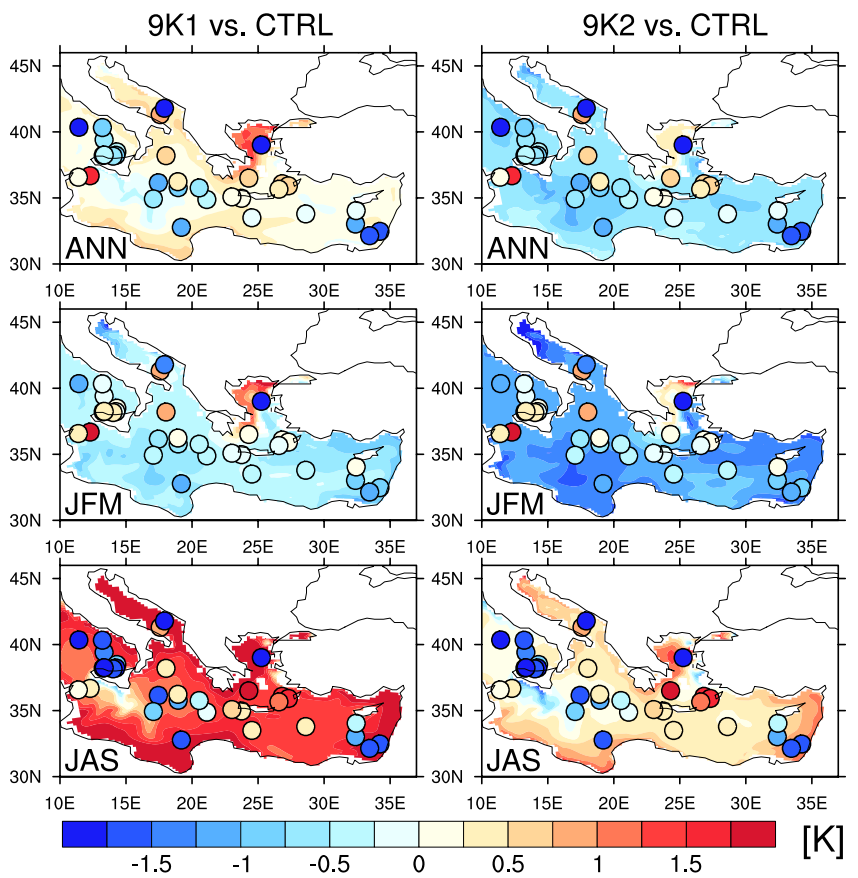

Fig. 19. Annual, winter (JFM) and summer (JAS) SST anomalies, reconstructed from proxy data (dots, Kucera et al. (2011)) vs. modelled one (background colour) for 9K1 vs. CTRL (left) and 9K2 vs. CTRL (right). 1st row displays annual SST anomalies, 2nd row displays winter SST anomalies, 3rd row displays summer SST anomalies.

Tyrrhenian and the eastern Levantine. We refer to this alternance of cold/warm/cold anomaly patterns from the west to the east as the "tripole". In summer, this reconstructed SST anomaly signal is much stronger than for annual mean. In fact, the reconstructed winter SST anomalies (Fig. 19, 2nd row) generally show a cooling, except for the Cretan and Sicilian regions which display a minor warming: this winter signal dampens the stronger summer signal and explains the smoother gradient of the reconstructed annual SST anomalies. Concerning the model ability to reproduce these spatial anomaly patterns, the model results are not consistent with the reconstructions. Whereas the tripole pattern is somewhat imaged by the $9 \mathrm{~K} 1$ simulation for the annual SST anomalies, the $9 \mathrm{~K} 2$ simulation is again consistently too cold. For the summer SST anomalies, the 9K1 experiment shows a rather homogeneous warming, but hardly any cooling of the middle Ionian and the Tyrrhenian. The 9K2 experiment shows a much weaker warming and is able to reproduce an enhanced warming pattern around Crete. The modelled winter SST anomalies do not show the warming around Sicily, and the 9K2 experiment simulates a far too strong cooling over the entire basin.

Two points are important to notice at this stage of the analysis: the simulated temperature signal decreases very strongly with depth in the upper part of the water column 

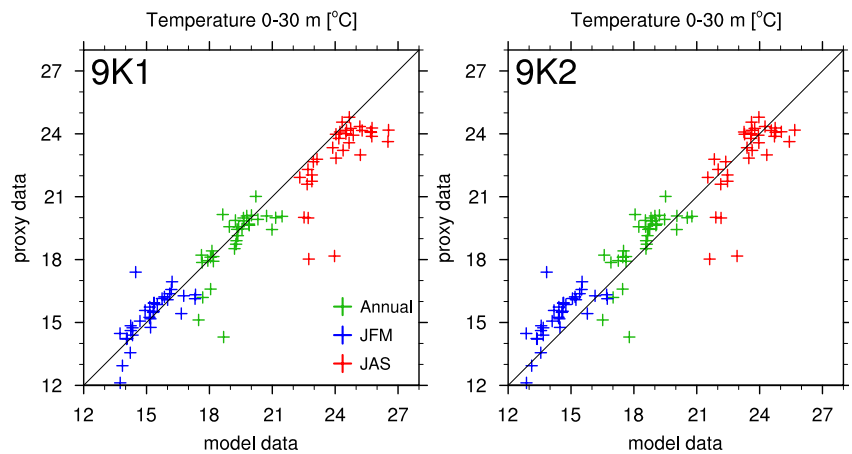

Fig. 20. Comparison of modelled $T_{0-30}$ with $T_{0-30}$ reconstructed from proxy data (Kucera et al., 2011) for 9K1 (left) and 9K2 (right). Annual mean, winter (JFM) and summer (JAS) are considered.

during the summer season, due to strong stratification (Fig. 10). Moreover, the foraminifera used for the SST reconstructions are not limited to the 10-m depth of the calibration, but inhabit the entire mixed layer and some live even below it (Bé et al., 1977; Schiebel and Hemleben, 2005). They are, thus, likely to record subsurface temperatures as well, which are colder than the surface temperature in summer.

To account for this, we decide to consider subsurface temperature for our comparison. The strong depth dependency of both annual and summer temperature signals leads us to propose a new depth-integrated approach of interpreting SSTs derived from foraminifera census data. Moreover, the temperature anomaly patterns recorded by the reconstruction closely resemble the patterns recorded at subsurface depth in our simulation, as shown in Sect. 4.3.2. This strengthens our motivation to test an approach which integrates subsurface temperature to validate model data with temperature reconstructions from proxy data.

\subsubsection{A depth-integrated approach for model-proxy comparison of upper-ocean temperature}

In this section, we propose an alternative approach to perform a comparison of surface temperature signal between output from model simulations and reconstructions based on planktonic foraminifera.

We consider temperatures averaged over a larger depth interval for our model-proxy comparison instead of restricting it to a narrowly defined SST signal. As an example, we choose to integrate the temperature over the depth interval between 0 and $30 \mathrm{~m}$ (henceforth $T_{0-30}$ ), where the vertical temperature gradient is strongest. We do not claim that 0 $30 \mathrm{~m}$ is the range of depth which should always be chosen, but we rather aim to highlight the need to consider a broader interval of depth which depends on the living depth of the foraminifera. The interval of depth chosen to integrate the temperature signal should be informed by the oceanographic conditions of a given region and the ecology of the planktonic species used.
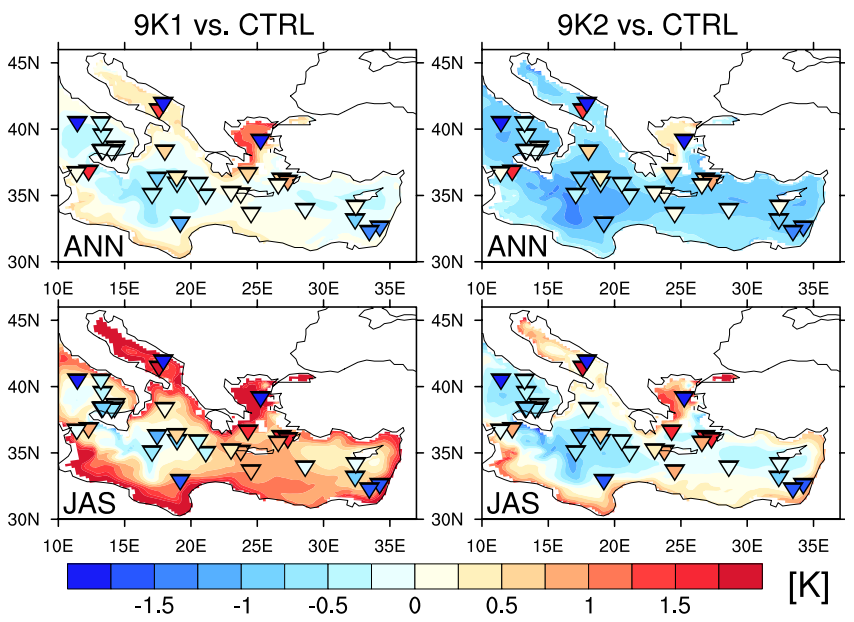

Fig. 21. Annual and summer (JAS) $T_{0-30}$ anomalies, calculated from SST reconstructions from proxy data (triangles, Kucera et al. (2011)) vs. modelled one (background colour) for 9K1 vs. CTRL (left) and 9K2 vs. CTRL (right). 1st row displays annual $T_{0-30}$ anomalies, 2 nd row displays summer $T_{0-30}$ anomalies.

The proxy temperatures are, in a strict sense, only valid for $10 \mathrm{~m}$ depth. As for many of the core locations, no core top estimates of the pre-industrial climate are available, anomalies versus climatologies for this depth have been used. However, this approach is not adequate in obtaining reconstructed anomalies of $T_{0-30}$ signal: the present-day climatology for $T_{0-30}$ can easily be calculated from the same climatology, but the proxy data should have been estimated with $T_{0-30}$ as the base too, which is beyond the scope of this paper. As a simple approximation, we calculate a linear regression between $T_{10}$, which has been originally used to fit the proxy data, and $T_{0-30}$ from the World Ocean Atlas dataset. Only data from the Mediterranean and the North Atlantic are used for this calculation (box selected between $30^{\circ}$ and $50^{\circ}$ north and $-20^{\circ}$ and $37^{\circ}$ east). We apply this relation to the reconstructed data and get a new set of reconstructions for $T_{0-30}$. The functions applied are the following: $T_{0-30}=0.97 T_{10}+$ 0.29 for annual temperatures, $T_{0-30}=0.99 T_{10}+0.015$ for winter and $T_{0-30}=0.9 T_{10}+1.45$ for summer. The $R^{2}$ is higher than 0.977 for all three scalings. The root mean square deviation (RMSD) of the obtained $T_{0-30}$ is $0.41 \mathrm{~K}$ for summer, $0.02 \mathrm{~K}$ for winter and $0.17 \mathrm{~K}$ for annual mean. In winter, the mixed layer depth is generally deeper than $30 \mathrm{~m}$ and the vertical temperature gradient is small. For this season, the results for $T_{0-30}$ are not substantially different from the results for $T_{10}$. Thus, the discussion will rather focus on summer and annual mean.

The new model-proxy comparison for the absolute $T_{0-30}$ is displayed in Fig. 20. It exhibits the fit between the reconstructions and the model data at each core location; for annual mean, winter (JFM) and summer (JAS). The new comparison shows a great improvement, especially for the summer season, when the strongest discrepancies were found 
Table 3. Mean error and mean biases [K].

\begin{tabular}{|c|c|c|c|c|c|}
\hline & & \multicolumn{2}{|c|}{ SST } & \multicolumn{2}{|c|}{$T_{0-30}$} \\
\hline & & $9 \mathrm{~K} 1$ & $9 \mathrm{~K} 2$ & $9 \mathrm{~K} 1$ & $9 \mathrm{~K} 2$ \\
\hline \multirow{2}{*}{ Annual mean } & Error (RMSD) & 1.46 & 1.04 & 1.11 & 1.10 \\
\hline & Mean bias & 1.02 & 0.19 & 0.35 & -0.38 \\
\hline \multirow{2}{*}{ Winter (JFM) } & Error (RMSD) & 1.03 & 1.20 & 1.03 & 1.23 \\
\hline & Mean bias & 0.00 & -0.66 & 0.00 & -0.71 \\
\hline \multirow{2}{*}{ Summer (JAS) } & Error (RMSD) & 3.10 & 2.16 & 1.83 & 1.34 \\
\hline & Mean bias & 2.81 & 1.73 & 1.29 & 0.50 \\
\hline \multirow{2}{*}{ Averaged } & Error (RMSD) & 2.06 & 1.55 & 1.37 & 1.23 \\
\hline & Mean bias & 1.27 & 0.42 & 0.55 & -0.59 \\
\hline
\end{tabular}

in the previous strict SST comparison (Fig. 18). For both simulations, the biases between modelled and reconstructed $T_{0-30}$ are generally below $\pm 1 \mathrm{~K}$, except for the data located in the Adriatic and in the Aegean Seas (Fig. S3 in the Supplement).

Figure 21 displays the new comparison for the $T_{0-30}$ anomalies (9 ka BP vs. CTRL) simulated by the model and recorded by the proxy indicators. The reconstructed summer $T_{0-30}$ anomalies do show the west-east tripole (Fig. 21, 2nd row). However, in the Tyrrhenian, the central Ionian and the eastern Levantine, the cooling signal is less pronounced than with the strict SST reconstructions; this is in agreement with the modelled signal of the $9 \mathrm{~K} 2$ simulation. The cold anomalies simulated by $9 \mathrm{~K} 1$ in these regions are weak and even missing for the eastern Levantine. The new $T_{0-30}$ reconstructions show a more homogeneous warming around Crete. This warming is simulated in the $9 \mathrm{~K} 1$ experiment, but the warmest anomalies are located in the southwestern Levantine. The $9 \mathrm{~K} 2$ experiment displays a very weak cooling in the Cretan region and a moderate warming in the southwestern Levantine. The model produces the warmest anomalies in the southwestern Levantine rather than in the Cretan region because the downwelling of warm surface water is simulated too far south. Nevertheless, in few locations, the anomalies ( $9 \mathrm{ka}$ BP vs. present-day) of estimated $T_{0-30}$ reconstructions show a signal which is lower than the RMSD of the estimated summer $T_{0-30}$ signal $(0.41 \mathrm{~K})$. These results should, thus, be interpreted cautiously.

It is worth mentioning that if the modelled Etesian winds had a stronger westerly component, and had their core centred over the east Aegean (as it is recorded by the observations), the downwelling of warm surface water would occur around Crete, leading to warm subsurface anomalies there rather than in the southwestern Levantine (as shown in Fig. 16, right). This would also improve the agreement between model and proxies, showing a modelled warming more centred around Crete, consistently with the reconstructed signal.
To summarize the results from the model-proxy comparison and to highlight the added value from the novel integrated approach, Table 3 compiles the mean bias and the mean standard error (RMSD) for (i) the SST comparison and (ii) the $T_{0-30}$ comparison. The most obvious improvement is for summer, when both $9 \mathrm{~K} 1$ and $9 \mathrm{~K} 2$ simulations reach a much lower mean bias with the $T_{0-30}$ comparison. The RMSD is also clearly improved. As expected, there is hardly any difference between the SST and $T_{0-30}$ comparisons for winter, because the small temperature gradient during this season leads to similar results. If we average the mean bias and the RMSD for the three considered periods (winter, summer and annual mean), it is clear that the $T_{0-30}$ comparison leads to a better match. In our point-of-view, the experiment $9 \mathrm{~K} 2$ fits the reconstructions the best. Although the mean bias is slightly higher than for $9 \mathrm{~K} 1(-0.59 \mathrm{~K}$ vs. $0.55 \mathrm{~K})$, the RMSD value of $9 \mathrm{~K} 2$ is lower $(1.23 \mathrm{~K}$ vs. $1.37 \mathrm{~K})$.

These results confirm the hypothesis that the model-proxy comparison should involve a temperature signal integrated over a wider range of subsurface depth, consistent with the range of living depths of the planktonic foraminifera used, instead of restricting the comparison to the SST. Ideally, a new transfer function should be used to perform the reconstructions, taking into account an integrated temperature signal whose depth range should be previously determined.

The simulation 9K2 seems to represent an upper-ocean climate somewhat more realistic than the $9 \mathrm{~K} 1$ simulation which simulates in general a too warm climate, due to the fact that the forcing used for this simulation does neither include the cooling effect from the melting glaciers nor from the lower $p \mathrm{CO}_{2}$.

\section{Conclusions}

We have modelled the upper ocean climate of the Eastern Mediterranean for the Holocene Insolation Maximum (9 ka BP) with a regional OGCM forced by daily atmospheric 
data derived from global simulations. Two experiments have been carried out: 9K1 with changes in solar forcing only and $9 \mathrm{~K} 2$ with changes in solar forcing, atmospheric $p \mathrm{CO}_{2}$ and topography (presence of major ice sheets).

We analysed the mechanisms responsible for the enhanced subsurface summer warming observed in the Cretan/West Levantine region during the HIM, which is recorded by both the model and proxy data. The drivers of this warming are found to be a combination of (i) enhanced downwelling (due to stronger Ekman transport) and wind mixing, both due to strengthened Etesian winds, and (ii) enhanced vertical temperature gradient due to the stronger seasonal cycle in the Northern Hemisphere. Together, these processes induce a stronger heat transfer from the surface to the subsurface during late summer in the western Levantine and are responsible for the heat piracy simulated in this region.

We used SST reconstructed from planktonic foraminifera assemblages to validate our HIM simulations, but found it necessary to integrate modelled SST over a wider depth range to account for variable habitat depth. We believe that this is how surface temperature comparisons between model data and reconstructions from foraminifera should be performed. This novel depth-integrated approach strongly improved the agreement between the reconstructions and the modelling results. The currently used technique to reconstruct temperature from planktonic foraminifera is likely inadequate for time periods when the vertical temperature gradient was different from today, which is likely to have been the case in the isolated Mediterranean Sea for periods with changing insolation. Ideally, the transfer function should be newly calculated for the temperature integrated over the considered depth range including subsurface.

We believe that the dipole in summer temperature anomalies identified in the Levantine by both simulations and reconstructions is a general feature of time periods with enhanced insolation. Such a characteristic response is, thus, expected for other past time slices like e.g. the Eemian.

\section{Supplementary material related to this article is available online at: http://www.clim-past.net/7/1103/2011/ cp-7-1103-2011-supplement.pdf.}

Acknowledgements. This study was carried out in the frame of the subproject HOBIMED part of the cooperative project INTERDYNAMIK, funded by the DFG. Computational resources were provided by the DKRZ. We thank the ESF-funded program MedCLIVAR for its support. Comments from Steffen Tietsche, Alfredo Izquierdo and the three anonymous reviewers were really helpful to improve the manuscript.

The service charges for this open access publication have been covered by the Max Planck Society.

Edited by: H. Goosse

\section{References}

Aksu, A. E., Hiscott, R. N., Yasar, D., Isler, F. I., and Marsh, S.: Seismic stratigraphy of Late Quaternary deposits from the southwestern Black Sea shelf: evidence for non-catastrophic variations in sea-level during the last similar to $10000 \mathrm{yr}$, Mar. Geol., 190, 61-94, 2002.

Andersson, A., Bakan, S., Fennig, K., Grassl, H., Klepp, C., and Schulz, J.: Hamburg Ocean Atmosphere Parameters and Fluxes from Satellite Data - HOAPS-3 - monthly mean, World Data Center for Climate, doi:10.1594/WDCC/HOAPS3_MONTHLY, 2007.

Arakawa, A. and Lamb, V. R.: Computational design of the basic dynamical processes of the UCLA general circulation model, Methods Comput. Phys., 17, 173-265, 1977.

Astraldi, M., Gasparini, G. P., Sparnocchia, S., Moretti, M., and Sansone, E.: The characteristics of the water masses and the water transport in the Sicily Strait at long time scales, Bulletin de l'Institut Oceanographique (Monaco), 95-115, 1996.

Baschek, B., Send, U., Lafuente, J. G., and Candela, J.: Transport estimates in the Strait of Gibraltar with a tidal inverse model, J. Geophys. Res.-Oceans, 106, 31033-31044, 2001.

Bé, A. W. H., Jongebloed, W. L., and Mclntyre, A.: X-ray microscopy of Recent planktonic Foraminifera., J. Paleont., 43, 1384-1396, 1977.

Berrisford, P., Dee, D., Fielding, K., Fuentes, M., Kallberg, P., Kobayashi, S., and Uppala, S.: The ERA-Interim Archive. ERA Report Series No. 1, Tech. rep., ECMWF: Reading, UK (available from www.ecmwf.int/publications), 2009.

Béthoux, J. P.: Budgets Of The Mediterranean Sea - Their Dependance On The Local Climate And On The Characteristics Of The Atlantic Waters, Oceanologica Acta, 2, 157-163, 1979.

Beuvier, J., Sevault, F., Herrmann, M., Kontoyiannis, H., Ludwig, W., Rixen, M., Stanev, E., Béranger, K., and Somot, S.: Modeling the Mediterranean Sea interannual variability during 19612000: Focus on the Eastern Mediterranean Transient, J. Geophys. Res.-Oceans, 115, C08017, doi:10.1029/2009JC005950, 2010.

Bigg, G. R.: An Ocean General-Circulation Model View Of The Glacial Mediterranean Thermohaline Circulation, Paleoceanography, 9, 705-722, 1994.

Braconnot, P., Otto-Bliesner, B., Harrison, S., Joussaume, S., Peterchmitt, J.-Y., Abe-Ouchi, A., Crucifix, M., Driesschaert, E., Fichefet, Th., Hewitt, C. D., Kageyama, M., Kitoh, A., Lan, A., Loutre, M.-F., Marti, O., Merkel, U., Ramstein, G., Valdes, P., Weber, S. L., Yu, Y., and Zhao, Y.: Results of PMIP2 coupled simulations of the Mid-Holocene and Last Glacial Maximum Part 1: experiments and large-scale features, Clim. Past, 3, 261277, doi:10.5194/cp-3-261-2007, 2007.

Brody, L. R. and Nestor, M. J. R.: Regional forecasts for the Mediterranean basin, Tech. Rep. 80-10, Naval Environmental Prediction Research Facility, Monterey, California, USA, 1985.

Bryden, H. L. and Kinder, T. H.: Steady 2-Layer Exchange Through The Strait Of Gibraltar, Deep-Sea Res., 38, S445-S463, 1991.

Bryden, H. L., Candela, J., and Kinder, T. H.: Exchange Through The Strait Of Gibraltar, Prog. Oceanogr., 33, 201-248, 1994.

Cramp, A. and O'Sullivan, G.: Neogene sapropels in the Mediterranean: a review, Mar. Geol., 153, 11-28, 1999.

da Silva, A., Young, C., and Levitus, S.: Atlas of surface marine data, 1-5, NOAA Atlas NESDIS, US Department of Commerce, NOAA, NESDIS, 1994. 
D’Ortenzio, F., Iudicone, D., de Boyer Montegut, C., Testor, P., Antoine, D., Marullo, S., Santoleri, R., and Madec, G.: Seasonal variability of the mixed layer depth in the Mediterranean Sea as derived from in situ profiles, Geophys. Res. Lett., 32, L12605, doi:10.1029/2005GL022463, 2005.

Emeis, K. C., Struck, U., Schulz, H. M., Rosenberg, R., Bernasconi, S., Erlenkeuser, H., Sakamoto, T., and Martinez-Ruiz, F.: Temperature and salinity variations of Mediterranean Sea surface waters over the last 16,000 years from records of planktonic stable oxygen isotopes and alkenone unsaturation ratios, Palaeogeogr. Palaeoclimatol., 158, 259-280, 2000.

Garzoli, S. and Maillard, C.: Winter Circulation In The Sicily And Sardinia Straits Region, Deep-Sea Res., 26, 933-954, 1979.

Hayes, A., Kucera, M., Kallel, N., Sbaffi, L., and Rohling, E. J.: Glacial Mediterranean sea surface temperatures based on planktonic foraminiferal assemblages, Quaternary Sci. Rev., 24, 9991016, 2005.

Herrmann, M., Somot, S., Sevault, F., Estournel, C., and Deque, M.: Modeling the deep convection in the northwestern Mediterranean Sea using an eddy-permitting and an eddy-resolving model: Case study of winter 1986-1987, Journal Of Geophysical ResearchOceans, 113, C04 011, doi:10.1029/2006JC003991, 2008.

Kallel, N., Paterne, M., Labeyrie, L., Duplessy, J. C., and Arnold, M.: Temperature and salinity records of the Tyrrhenian Sea during the last 18,000 years, Palaeogeogr. Palaeoclimatol., 135, 97 108, 1997.

Kalnay, E., Kanamitsu, M., Kistler, R., Collins, W., Deaven, D., Gandin, L., Iredell, M., Saha, S., White, G., Woollen, J., Zhu, Y., Chelliah, M., Ebisuzaki, W., Higgins, W., Janowiak, J., Mo, K. C., Ropelewski, C., Wang, J., Leetmaa, A., Reynolds, R., Jenne, R., and Joseph, D.: The NCEP/NCAR 40-year reanalysis project, B. Am. Meteor. Soc., 77, 437-471, 1996.

Kucera, M., Rohling, E. J., Hayes, A., Hopper, L. G. S., Kallel, N., Buongiorno Nardelli, B., Adloff, F., and Mikolajewicz, U.: Sea surface temperature of the Mediterranean Sea during the early Holocene insolation maximum, Clim. Past, in prep., 2011.

Lascaratos, A.: Estimation Of Deep And Intermediate Water Mass Formation Rates In The Mediterranean-Sea, Deep-Sea Res., 40, 1327-1332, 1993.

Levitus, S.: Climatological Atlas of the World Ocean, NOAA/ERL GFDL, Professional Paper 13, Princeton, N.J., 173 pp. (NTISPB83-184093), 1982.

Levitus, S., Boyer, T. P., Conkwright, M., Johnson, D., O’Brian, T., Antonov, J., Stephens, C., and Gelfield, R.: Introduction. World Ocean Database 1998. Vol. 1, NOAA Atlas NESDIS 18, 346 pp., 1998.

Ludwig, W., Dumont, E., Meybeck, M., and Heussner, S.: River discharges of water and nutrients to the Mediterranean and Black Sea: Major drivers for ecosystem changes during past and future decades?, Progr. Oceanogr., 80, 199-217, 2009.

Marsland, S. J., Haak, H., Jungclaus, J. H., Latif, M., and Roske, F.: The Max-Planck-Institute global ocean/sea ice model with orthogonal curvilinear coordinates, Ocean Modell., 5, 91-127, 2003.

MEDAR-Group: MEDATLAS 2002 Database, Cruise Inventory, observed and analysed data of temperature and bio-chemical parameters, IFREMER Edition (4 CDRom), 2002.

Meijer, P. Th. and Dijkstra, H. A.: The response of Mediterranean thermohaline circulation to climate change: a minimal model,
Clim. Past, 5, 713-720, doi:10.5194/cp-5-713-2009, 2009.

Meijer, P. Th. and Tuenter, E.: The effect of precession-induced changes in the Mediterranean freshwater budget on circulation at shallow and intermediate depth, J. Marine Syst., 68, 349-365, 2007.

Mercone, D., Thomson, J., Croudace, I. W., Siani, G., Paterne, M., and Troelstra, S.: Duration of S1, the most recent sapropel in the eastern Mediterranean Sea, as indicated by accelerator mass spectrometry radiocarbon and geochemical evidence, Paleoceanography, 15, 336-347, 2000.

Meteorological-Office: Weather in the Mediterranean, Vol. I., General Meteorology., H. M. S. O. London, 2 Edn., 1962.

Mikolajewicz, U.: Modeling Mediterranean Ocean climate of the Last Glacial Maximum, Clim. Past, 7, 161-180, doi:10.5194/cp7-161-2011, 2011

Mikolajewicz, U., Groger, M., Maier-Reimer, E., Schurgers, G., Vizcaino, M., and Winguth, A. M. E.: Long-term effects of anthropogenic $\mathrm{CO}_{2}$ emissions simulated with a complex earth system model, Clim. Dynam., 28, 599-631, 2007.

Myers, P. G.: Flux-forced simulations of the paleocirculation of the Mediterranean, Paleoceanography, 17, 1009, doi:10.1029/2000PA000613, 2002.

Myers, P. G. and Rohling, E. J.: Modeling a 200-yr interruption of the Holocene Sapropel S-1, Quaternary Res., 53, 98-104, 2002.

Myers, P. G., Haines, K., and Rohling, E. J.: Modeling the paleocirculation of the Mediterranean: The last glacial maximum and the Holocene with emphasis on the formation of sapropel S-1, Paleoceanography, 13, 586-606, 1998.

Pacanowski, R. C. and Philander, S. G. H.: Parameterization Of Vertical Mixing In Numerical-Models Of Tropical Oceans, J. Phys. Oceanogr., 11, 1443-1451, 1981.

Peltier, W. R.: Global glacial isostasy and the surface of the ice-age earth: The ice-5G (VM2) model and grace, Annu. Rev. Earth P1. Sc., 32, 111-149, 2004.

Pinardi, N. and Masetti, E.: Variability of the large scale general circulation of the Mediterranean Sea from observations and modelling: a review, Palaeogeogr. Palaeoclimatol., 158, 153-174, 2000.

Roeckner, E., Buml, G., Bonaventura, L., Brokopf, R., Esch, M., Giorgetta, M., Hagemann, S., Kirchner, I., Manzini, L. K. E., Rhodin, A., Schlese, U., Schulzweida, U., and Tompkins, A.: The atmospheric general circulation model ECHAM5, Tech. Rep., 349, Max Planck Institute for Meteorology, Hamburg, 2003.

Rohling, E. J.: Review And New Aspects Concerning The Formation Of Eastern Mediterranean Sapropels, Mar. Geol., 122, 1-28, 1994

Rohling, E. J. and Hilgen, F. J.: The Eastern Mediterranean Climate At Times Of Sapropel Formation - A Review, Geol. Mijnbouw, 70, 253-264, 1991.

Rossignol-Strick, M.: African Monsoons, An Immediate Climate Response To Orbital Insolation, Nature, 304, 46-49, 1983.

Ryan, W. B. F., Pitman, W. C., Major, C. O., Shimkus, K., Moskalenko, V., Jones, G. A., Dimitrov, P., Gorur, N., Sakinc, M., and Yuce, H.: An abrupt drowning of the Black Sea shelf, Mar. Geol., 138, 119-126, 1997.

Schiebel, R. and Hemleben, C.: Modern planktic foraminifera, Palaeont. Z., 79, 135-148, 2005.

Schmiedl, G., Kuhnt, T., Ehrmann, W., Emeis, K. C., Hamann, Y., 
Kotthoff, U., Dulski, P., and Pross, J.: Climatic forcing of eastern Mediterranean deep-water formation and benthic ecosystems during the past 22000 years, Quaternary Sci. Rev., 29, 30063020, 2010.

Simmons, A. S., Uppala, D. D., and Kobayashi, S.: ERA-interim: new ECMWF reanalysis products from 1989 onwards, ECMWF News, 110, 29-35, 2007.

Somot, S.: Modélisation climatique du bassin méditerranéen: variabilité et scénarios de changement climatique, Ph.D. thesis, Université de Toulouse III, 2005.

Soulet, G., Menot, G., Lericolais, G., and Bard, E.: A revised calendar age for the last reconnection of the Black Sea to the global ocean, Quaternary Sci. Rev., 30, 1019-1026, 2011.

Sperling, M., Schmiedl, G., Hemleben, C., Emeis, K. C., Erlenkeuser, H., and Grootes, P. M.: Black Sea impact on the formation of eastern Mediterranean sapropel S1, Evidence from the Marmara Sea, Palaeogeogr. Palaeoclimatol., 190, 9-21, 2003.
Stanev, E. V. and Peneva, E. L.: Regional sea level response to global climatic change: Black Sea examples, Global Planet. Changes, 32, 33-47, 2002.

Tsimplis, M. N. and Bryden, H. L.: Estimation of the transports through the Strait of Gibraltar, Deep-Sea Res., 47, 2219-2242, 2000.

von Storch, H. and Zwiers, F.: Statistical analysis in climate research, Cambridge University Press, Cambridge, 1999.

Vörösmarty, C., Fekete, B., and Tucker, B.: Global River Discharge, 1807-1991, Version. 1.1 RivDIS Data set., available at: http://www.daac.ornl.gov, from Oak Ridge National Laboratory Distributed Active Archive Center, Oak Ridge, Tennessee, USA, 1998. 